\title{
The immune signaling pathways of Manduca sexta
}

\author{
Xiaolong $\mathrm{Cao}^{1}$, Yan $\mathrm{He}^{1}$, Yingxia $\mathrm{Hu}^{1}$, Yang Wang ${ }^{1}$, Yun-Ru Chen ${ }^{2}$, \\ Bart Bryant ${ }^{3}$, Rollie J. Clem ${ }^{3}$, Lawrence M. Schwartz ${ }^{4}$, Gary Blissard ${ }^{2}$, Haobo Jiang ${ }^{1,} \dagger$ \\ ${ }^{1}$ Department of Entomology and Plant Pathology, Oklahoma State University, \\ Stillwater, OK 74078, USA \\ ${ }^{2}$ Boyce Thompson Institute, Cornell University, Ithaca, NY 14853, USA \\ ${ }^{3}$ Division of Biology, Kansas State University, Manhattan, KS 66506 \\ ${ }^{4}$ Department of Biology, University of Massachusetts, Amherst, MA 01003
}

Key words: insect immunity, RNA-Seq, transcriptome, gene annotation, expression profiling.

Abbreviations: Atg, autophagy-related protein; aPKC, atypical protein kinase $\mathrm{C}$; $\mathrm{CF}$, control fat body; $\mathrm{CH}$, control hemocytes; IF, induced fat body; IH, induced hemocytes; Deaf, deformed epidermal autoregulatory factor; Dnr1, defense repressor-1; Dsp1; Dorsal switch protein-1; ECSIT, evolutionarily conserved intermediate in Toll pathways; FPKM, fragments per kilobase of exon per million fragments mapped; GPRK, G protein-coupled receptor kinase; IAP, inhibitor of apoptosis; Imd, immunodeficiency; IKK, IкB kinase; JNK, Jun N-terminal kinase; Jra, Jun-related antigen; MAPK, mitogen-activated protein kinase; MASK, multiple ankyrin repeats single KH domain; ML, MD2-like; MLK, mixed-linage kinase; NFKB and $\mathrm{I} \kappa \mathrm{B}$, nuclear factor- $\kappa \mathrm{B}$ and its inhibitor; NTF, nuclear transport factor; PIAS, protein inhibitor of activated STAT; PIRK, poor Imd response upon knock-in; PVF, platelet-derived and vascular endothelial growth factor; PVR, PDGF/VEGF receptor; STAT, signal transducer and activator of transcription; PG and PGRP, peptidoglycan and peptidoglycan recognition protein; SUMO, small ubiquitin-like modifier; TAK, transforming growth factor $\beta$ activated kinase; TAMP, Toll activation mediating protein; TIR, Toll/interleukin-1 receptor; TRAF, tumor necrosis factor receptor-associated factor.

$\dagger$ Send correspondence to:

Haobo Jiang

Department of Entomology and Plant Pathology

Oklahoma State University

Stillwater, OK 74078

Telephone: (405)-744-9400

Fax: (405)-744-6039

E-mail: haobo.jiang@okstate.edu 


\section{Abstract}

Signal transduction pathways and their coordination are critically important for proper functioning of animal immune systems. Our knowledge of the constituents of the intracellular signaling network in insects mainly comes from genetic analyses in Drosophila melanogaster. To facilitate future studies of similar systems in the tobacco hornworm and other lepidopteran insects, we have identified and examined the homologous genes in the genome of Manduca sexta. Based on 1:1 orthologous relationships in most cases, we hypothesize that the Toll, Imd, MAPKJNK-p38 and JAK-STAT pathways are intact and operative in this species, as are most of the regulatory mechanisms. Similarly, cellular processes such as autophagy, apoptosis and RNA interference probably function in similar ways, because their mediators and modulators are mostly conserved in this lepidopteran species. We have annotated a total of 186 genes encoding 199 proteins, studied their domain structures and evolution, and examined their mRNA levels in tissues at different life stages. Such information provides a genomic perspective of the intricate signaling system in a non-drosophiline insect.

\section{Introduction}

Insects fight against invading pathogens and parasites via their innate immune system (Gillespie et al., 1997; Lemaitre and Hoffmann, 2007). Like other physiological processes, insect immune responses involve sensors, effectors, and signal transducers, linking pathogen recognition with cellular and humoral responses. Some of the responses occur in minutes while others involve transcriptional activation of genes that are not highly expressed under normal conditions, and thus may provide responses in hours to days. In the latter case, a relay system must exist to transduce the extracellular signals of wounding or invasion into the nuclei of cells, where transcriptional regulation occurs. If pathogens are sensed by receptors (e.g. PGRP-LC) on 
25 the cell surface, responses are more direct than if recognition occurs in hemolymph. In the latter 26 scenario, receptors (e.g. PGRP-SA) in hemolymph bind to the pathogens and initiate 27 extracellular signal transduction to generate active cytokines. The cytokines then interact with 28 their receptors on the cell surface to induce cellular responses including phagocytosis, encapsulation, apoptosis, autophagy, and synthesis of immune effectors (Strand, 2008; Jiang et al., 2010). Consequently, the intracellular signal transduction network is essential for mediating immune responses in insects.

Receptor-mediated Toll, Imd, MAPK-JNK-p38, JAK-STAT and other pathways are widely conserved in metazoans, functioning as regulators and mediators of humoral and cellular immune responses (Buchon et al., 2014). Extensive studies in Drosophila melanogaster have revealed many details of the signal transduction network. The Toll pathway was discovered in the screens that identified mutations in genes affecting the establishment of dorsoventral axis and

37 later found to regulate the expression of immunity-related genes through Dorsal and Dif, transcription activators of the Rel family (Valanne et al., 2011). Gram-positive bacteria and fungi trigger this pathway via an extracellular serine protease cascade that activates the cytokine Spätzle through limited proteolysis. This activated cytokine binds to the Toll receptor, leading to antimicrobial peptide synthesis and differentiation of certain hemocytes into lamellocytes. These

42 lamellocytes are capable of encapsulating and killing parasites such as parasitoid wasps 43 (Sorrentino et al., 2004). In the case of Gram-negative bacteria, DAP-type peptidoglycans (PGs) 44 elicit the Imd pathway via transmembrane PGRP-LC and intracellular signal mediators (Kaneko et al., 2006; Rämet et al., 2002). Activated Relish, another Rel factor, then migrates into the nucleus to turn on a set of immunity-related genes overlapping with that induced by Dorsal and

47 Dif (Imler and Hoffmann, 2001; Mellroth et al., 2005). Cytokines, growth factors, or stress 48 signals stimulate the MAPK-JNK-p38 pathway to regulate apoptosis, Imd pathway, and cell 
differentiation (Ragab et al., 2011; Chen et al., 2010; Dong et al., 2002). The JAK-STAT

50 pathway, RNA interference, autophagy and other defense mechanisms are involved in antiviral

51 responses (Kisseleva et al., 2002; Baeg et al., 2005; Kingsolver et al., 2013). Based on the

52 available information, these pathways are mostly conserved among insects but differences do

53 exist. For instance, the honeybee Apis mellifera has considerably fewer immunity-related genes

54 (Evans et al., 2006). A. mellifera has five Toll genes compared with the nine found in $D$.

55 melanogaster. The pea aphid Acyrthosiphon pisum lacks the entire Imd pathway (Gerardo et al.,

56 2010). With such plasticity observed among the few genomes available in the Insecta, it is

57 therefore critically important to examine and characterize the immune signaling components in

58 different major orders of insects.

59 Lepidoptera comprises about 160,000 described species of moths and butterflies in 126 families and 46 superfamilies (Kristensen et al., 2007). Larvae of many lepidopterans are serious

61 agricultural pests but they are susceptible and can be controlled by biological agents such as 62 entomopathogens (e.g. viruses, bacteria, fungi) and parasitoid wasps. Studies of lepidopteran 63 immune systems and the associated signaling pathways are extremely important for developing 64 effective biological control methods. Manduca sexta and Bombyx mori have been used as 65 powerful biochemical models to explore various aspects of innate immunity (Jiang et al., 2010). 66 Immunity-related genes in the silkworm were previously compared with those in $D$. 67 melanogaster, Anopheles gambiae and A. mellifera (Tanaka et al., 2008) and analyses of the $M$. 68 sexta hemocyte and fat body transcriptomes revealed a set of 232 genes encoding proteins for 69 pathogen recognition, signal transduction, microbe killing (Gunaratna and Jiang, 2013), and 70 modulation of mRNA levels in response to an immune challenge (Zhang et al., 2011). Recently, 71 the $M$. sexta genome assembly became available along with 52 RNA-Seq datasets of tissues at 72 various life stages ( $\mathrm{X}$ et al., 2015). To better understand immune signal transduction in this 
73 undomesticated pest species, we have annotated genes for the putative pathway members,

74 studied their expression patterns, and proposed a signal transduction network based on 1:1

75 orthology. The results represent working models for future studies on $M$. sexta and other

76 lepidopteran pests.

77

78 2. Materials and methods

2.1. Gene identification, sequence improvement, and feature prediction

Manduca Genome Assembly 1.0 and gene models in Manduca Official Gene Sets (OGS) 1.0 and 2.0 and Cufflinks Assembly 1.0 (X et al., 2015) were downloaded from Manduca Base

82 (ftp://ftp.bioinformatics.ksu.edu/pub/Manduca/). Protein sequences of the putative signal

83 transducers from M. sexta (Gunaratna and Jiang, 2013) and other insects were used as queries to

84 search Cufflinks 1.0, OGS 1.0 and OGS 2.0 using the TBLASTN algorithm

85 (http://darwin.biochem.okstate.edu/blast/blast_links.html). Hits with aligned regions longer than

8630 residues and identity over $40 \%$ were retained for retrieving corresponding cDNA sequences.

87 Errors resulting from problematic regions (e.g. NNN...) in the genome assembly were manually

88 corrected after BLASTN search of Manduca Oases and Trinity Assemblies 3.0 of the RNA-Seq

89 data (Cao and Jiang, 2015). The two genome-independent RNA-Seq assemblies were developed

90 to cross gaps between genome scaffolds or contigs and detect errors in the gene models. In some

91 complex cases, all exons of a gene were examined based on the GT-AG rule and sequence

92 alignment to identify the splicing junctions. Correct open reading frames in the improved

93 sequences were identified using ORF Finder (http://www.ncbi.nlm.nih.gov/gorf/gorf.html) and

94 validated by BLASTP search against GenBank (http://www.ncbi.nlm.nih.gov/) or Uniprot

95 (http://www.uniprot.org/). Signal peptides were predicted using SignalP4.1 (Petersen et al.,

96 2011). Conserved domain structures were identified using SMART (http://smart.embl- 
97 heidelberg.de/smart/set_mode.cgi) and InterProScan (http://www.ebi.ac.uk/Tools/pfa/iprscan/).

\subsection{Sequence alignment and phylogenetic analysis}

Multiple sequence alignments of immune signal transducers from $M$. sexta and other insects were performed using MUSCLE, a module of MEGA 6.0 (Tamura et al., 2013) at the following settings: refining alignment, gap opening penalty (-2.9), gap extension penalty (0), hydrophobicity multiplier (1.2), maximal iterations (100), UPGMB clustering (for iterations 1 and 2) and maximum diagonal length (24). The aligned sequences were used to construct neighbor-joining trees by MEGA 6.0 with bootstrap method for the phylogeny test (1000 replications, Poisson model, uniform rates, and complete deletion of gaps or missing data).

\subsection{Gene expression profiling}

Coding DNA sequences from the improved gene models were retrieved and employed as templates for mapping reads in the 52 M. sexta RNA-Seq datasets, representing mRNA samples from whole insects, organs or tissues at various developmental stages. Illumina reads ( $M$. sexta genome and transcriptome project; http://www.ncbi.nlm.nih.gov/bioproject /PRJNA81039) were trimmed to $50 \mathrm{bp}$ and mapped to the coding regions using Bowtie (0.12.8) (Langmead et al, 2009). Numbers of the mapped reads were used to calculate FPKM (fragments per kilobase of exon per million fragments mapped) values using RSEM (Li and Dewey, 2011). Hierarchical clustering of the $\log _{2}(\mathrm{FPKM}+1)$ values was performed using MultiExperiment Viewer (v4.9) (http://www.tm4.org/mev.html) with the Pearson correlation-based metric and average linkage clustering method. To study transcript level changes after immune challenge, the entire CDS set was used to search for corresponding contigs in the CIFH09 database (http://darwin.biochem.okstate.edu/blast/blast_links.html) (Zhang et al., 2011) by TBLASTN. The numbers of $\mathrm{CF}, \mathrm{CH}, \mathrm{IF}$, and $\mathrm{IH}$ reads $(\mathrm{C}$ for control, I for induced after injection of bacteria, F for fat body, $\mathrm{H}$ for hemocytes) assembled into these contigs were retrieved for normalization 
121 and calculation of $\mathrm{IF} / \mathrm{CF}$ and $\mathrm{IH} / \mathrm{CH}$ ratios. When a polypeptide sequence corresponded to two or 122 more contigs, sums of the normalized read numbers were used to calculate its relative mRNA 123 abundances in fat body and hemocytes (Gunaratna and Jiang, 2013).

\section{Results and discussion}

\subsection{Spätzle-1-7, cytokines with distinct structures, functions, and expression patterns}

There are seven genes encoding Spätzle-like proteins in M. sexta (Table 1), which differs from the number present in Tribolium castaneum (9), D. melanogaster (6), and A. gambiae (6), B. mori (3) and A. mellifera (2) (Tanaka et al., 2008). The M. sexta proteins contain a signal peptide, a 50 to 360-residue segment with 0 to 4 low complexity regions, and a cystine-knot cytokine domain (Fig. 1). For Spätzle-1, cleavage between QR and LG results in a dimer of the C-terminal fragment that induces antimicrobial peptide synthesis (An et al., 2010), presumably via a Toll receptor. While Spätzle-2-7 may be activated by trypsin-like serine proteases, Spätzle-3 and 5 can also be processed by furin-like enzymes next to their recognition sequences, RHAR and RPRR, respectively. The C-terminal fragments of Spätzle-3-6 contain an even number of Cys residues, which might allow them to possibly dimerize via additional disulfide bonds. Molecular modeling suggests that Spätzle-1-5 and 7 adopt a similar fold with three pairs of antiparallel $\beta$ strands stabilized by 3 or 4 intrachain disulfide bonds (data not shown). Phylogenetic analysis of the entire proteins indicates that Spätzle-3-6 each forms a tight group with their orthologs from the other insects (Fig. 1A), suggestive of conserved functions. From parallel studies (Cao et al., 2015; Rao et al., 2015; He et al., 2015), we have noticed that the mRNA levels of many

142 immunity-related genes in fat body and midgut greatly increase at the onset of wandering stage 143 and peak on day 1 of the pupal stage. This infection-independent gene up-regulation during 
145 Vilcinskas, 2008). Spätzle-1, 2 and 7 transcripts display this pattern with the highest FPKM 146 values of 224, 760 and 564, respectively (Fig. 2A). These three genes are induced upon immune 147 challenge, whereas Spätzle-3-6 mRNAs were detected only at very low levels (Gunaratna and 148 Jiang, 2013; Zhang et al., 2011; Table 2). Spätzle-1B mRNA level is low in ovary, higher in eggs 149 and down-regulated after hatching. In contrast, Spätzle-2 mRNA levels are high in ovary, lower in eggs, and become higher in $1^{\text {st }}$ instar larvae. The expression patterns of Spätzle-3 and 5 are

151 similar to each other. Spätzle-4 and 6 are almost exclusively produced in the midgut of $2^{\text {nd }}$ and $1523^{\text {rd }}$ instar larvae. The detection of Spätzle-2, 3, 5 and 7 mRNAs in head is interesting, since 153 154 155 156 Drosophila Toll6, Toll7 and Toll8 act as receptors of neurotrophins (Drosophila Spätzle-2, 3 and 5) (McIlroy et al., 2013; Ballard et al., 2013).

\subsection{Structure, expression, and evolution of Toll receptors}

Toll receptors are a group of transmembrane proteins with extracellular Leu-rich repeats (LRRs) and a cytoplasmic Toll/interleukin-2 receptor (TIR) homology domain (Fig. 3A). We have identified sixteen such genes and named them Toll1-6, 7_1-3, 8,9_1,9_2, 10_1-3 and 12 (Table 1). These names are based on and mostly consistent with their orthologs in B. mori (Tanaka et al., 2008). Toll1 is reported as an immune-inducible gene that is predominantly expressed in hemocytes (Ao et al., 2008b; Gunaratna and Jiang, 2013) (Table 2). Along with Toll2-5 and B. mori Toll3_1-3, M. sexta Toll1 is grouped with D. melanogaster Toll1, 3-5, A. gambiae Toll1A, 1B, 5A and 5B, and T. castaneum Toll1-4 (Fig. 3B). Nonetheless, M. sexta 164 Toll1, 3 and 4 have only 4 to 5 LRRs (Fig. 3B), instead of the 12 LRRs and 2 Cys-rich C165 terminal domains that are present in Drosophila Toll1. The mRNA levels of Toll1, 3 and 4 are very low in the 52 libraries (Fig. 2A). Hence, the putative roles as Spätzle-1 or 2 receptors need 167 validation. In contrast, Toll2 and 5 transcripts are highly abundant in fat body and their profiles of expression are closely similar to those of Dorsal, Serpent and Spätzle-1B. Interestingly, 
Manduca Dorsal and Serpent may interact with each other to activate moricin gene transcription (Rao et al., 2011). Toll2 and 5 containing a Cys-rich C-terminal domain, are more similar in domain structure to Drosophila Toll1. Based on this and other evidence, we suggest M. sexta Toll2 and 5 are better candidates than Toll1 as receptors of Spätzle-1, 2 and 7. In $D$. melanogaster, Toll6, 7 and 8 (i.e. Tollo) are involved in neurotrophism (McIlroy et al., 2013; Ballard et al., 2013) and recent studies suggest that Toll7 may also be a pattern recognition receptor for vesicular stomatitis virus, activating cellular autophagy of the virus (Nakamoto et al., 2012). Their orthologous genes (Toll6, 7_1-3 and 8) are expressed in heads at levels higher than other tissues (Fig. 2A) and may play similar roles in $M$. sexta. The $M$. sexta Toll9_1 mRNA levels are high in Malpighian tubules of pre-wandering larvae and adults, as well as in midgut of feeding larvae. Human myeloid differentiation factor-2 (MD2) forms a complex with Toll-like receptor-4 to recognize lipopolysaccharide and lead to inflammation and cytokine production. A MD2-like protein (ML1) from A. gambiae specifically regulates the resistance to Plasmodium falciparum (Dong et al., 2006). We have identified five MD2-like proteins (MLs) in M. sexta, which contain a signal peptide and may increase binding specificity of the Toll receptors (Ao et al., 2008a).

Despite the fact that the coding regions being 2.2 to $4.0 \mathrm{~kb}$ in length, half of the 16 genes (Toll6, 7_1-3, 8, 10_1-3) only contain a single exon (Fig. 3C). They correspond 1:1 with their orthologous genes on chromosome 23 in B. mori. M. sexta Toll7_1, 10_3, 10_2, 10_1 and 6 on Scaffold (S) 00066 have the same orientations as those in the silkworm, flanked by Toll7_3 (S00185), 7_2 (S00183), and 8 (S00166) (Fig. 3C). When we compared the orthologous genes in A. gambiae, D. melanogaster and T. castaneum, similar gene orders were found. These

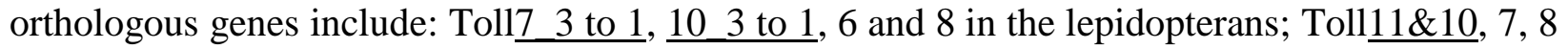
and 6 in the mosquito; Toll $2 \& 7,8$ and 6 in the fruit fly; Toll6, 8, 10, and 7 in the beetle. The 
193 194 195 196 197 198 199 200 201

202 203 204 205 206 207 208 209 210 211

underlined genes result from lineage-specific gene duplications. Except for AgToll8, TcToll8 and TcToll10 (with 5, 2 and 2 exons, respectively), the remaining genes are intronless. In comparison, MsToll1-5 have 7 or 8 exons, BmToll3_1-3 have 7, 5 and 8 exons, DmToll1, 3-5 have 2 or 4 exons, AgToll1A, 1B, 5A and 5B have 3 exons, and TcToll1-5 have 3 or 4 exons. Together, these observations reveal a dramatic evolutionary history of this ancient family of genes along the lineages of holometabolous insects.

\subsection{Intracellular members of the Toll pathway and their regulation}

We have identified 1:1 orthologs for most of the intracellular pathway members and modulators known so far. These include MyD88, Tube, Pelle, Pellino, Cactus, G protein-coupled receptor kinase-2 (GPRK2), Tollip-1\&2, Cactin, Aos, Uba2, Smt3, Lesswright, and deformed epidermal autoregulatory factor-1 (Deaf1) (Fig. 4A, Table 1) in Drosophila. In the current model, activated Toll receptor associates with its adaptor MyD88 via their TIR domains. MyD88, Tube and Pelle (a kinase-like protein) form a complex via their death domains to phosphorylate Cactus. Pellino, with a RING E3 ubiquitin ligase domain, may ubiquitinate Pelle to enhance the Toll signaling. Unlike its ortholog in the fruit fly, the C-terminal Ser/Thr protein kinase domain of $M$. sexta Tube is predicted to be active catalytically and thus, actively involved in the pathway activation. The phosphorylation of Cactus by Pelle and perhaps Tube, causes it to dissociate from Dorsal or Dif become polyubiquitinated and degraded by the proteasome. Dorsal and Dif appear to be the products of a lineage-specific gene duplication (data not shown). GPRK2 may interact with Cactus to enhance signaling. Atypical protein kinase $\mathrm{C}(\mathrm{aPKC})$, together with its partners Ref2P and TRAF2 (TNF-receptor-associated factor-2), may interact with Pelle and directly activate Dorsal/Dif (Avila et al., 2002). Free, active Dorsal/Dif translocates into the nucleus to activate target gene transcription along with Deaf1 and other transcription factors (e.g. U-shaped and Toll activation mediating protein, TAMP). This pathway is likely regulated at other steps. 
217 For instance, Tollips may associate with the Toll receptor and suppress the kinase activity of 218 Pelle (Zhang and Ghosh, 2002). In D. melanogaster, Cactin may bind Cactus to block its 219 function and cause embryonic ventralization (Lin et al., 2000). Conjugation of Dorsal/Dif by 220 Smt3, a small ubiquitin-like modifier (SUMO), may potentiate function of Dorsal/Dif (Bhaskar 221 et al., 2002). Aos1 and Uba2 may form a dimer which acts as an E1 SUMO-activating enzyme 222 (Paddibhatla et al., 2010). The Lesswright homolog of Ubc9, an E2 SUMO-conjugating enzyme, 223 negatively impacts the pathway (Chiu et al., 2005). The E3 SUMO ligase, Ulp1 peptidase and its 224 helper Kurtz, reduces SUMO conjugation and response level of Dorsal/Dif-induced genes 225 (Anjum et al., 2013).

Three Dorsal and two Dif variants are generated via alternative splicing (Table 1). The major

227 Dorsal A is widely produced in tissues whereas B- and C-forms are preferentially expressed in 228 fat body and head, respectively (Fig. 2A). Dif mRNA levels are lower compared to Dorsal. Like 229 MyD88, Aos1 and Smt3, Manduca Tube, Pelle, Pellino, Lesswright, Uba2, Ref2Ps, aPKC-A, 230 TRAF2, Cactus, Dorsal-A, ML2, cactin, Tollip-1 and 2 are widely expressed in all the tissues 231 examined. However, mRNA levels of the latter genes (Tube through Tollip-2) increase 232 considerably in fat body during the wandering stage and reach peaks in pupae at day 1. As well, 233 most of these genes are induced by $24 \mathrm{~h}$ following an immune challenge (Table 2).

\subsection{The Imd pathway, JNK branch, and their regulation}

The Imd pathway, considered specific for Gram-negative bacteria, regulates the transcription 236 of a set of immunity-related genes that overlaps with that controlled by the Toll pathway (Kleino 237 and Silverman, 2014). This pathway is also branched to JNK and apoptosis (Fig. 4B). We have 238 identified 1:1 orthologs for nearly all of the pathway components (Table 1) and, therefore, 239 propose that the $M$. sexta Imd pathway is triggered by DAP-PG, a component of the cell wall in 240 most Gram-negative bacteria as well as Gram-positive Bacillus and Listeria species. Since there 
241 is no PGRP-LE ortholog in the moth (Zhang et al., 2015), membrane-bound PGRP-LCa and LCb

242 may work together to detect them. The longer splicing variant LCa contains two transmembrane

243 domains, raising the possibility that it detects intracellular bacteria. Upon DAP-PG binding, a

244 cytosolic portion of these variants may interact with the adaptor Imd and then FADD through

245 their death domains. FADD recruits Dredd, the mammalian caspase-8 homolog, which cleaves

246 Imd and Relish (Ertürk-Hasdemir et al., 2009) or a pro-caspase that leads to apoptosis. Cleaved

247 Imd is susceptible to ubiquitination by IAP2 (inhibitor of apoptosis-2, an E3 ubiquitin ligase),

248 Uev1A, Ubc13/Bendless and Ubc5/Effete (E2 ubiquitin-conjugating enzymes) (Paquette et al.,

249 2010). Following ubiquitination, Imd likely recruits transforming growth factor $\beta$-activated

250 kinase-1 (TAK1) and its binding protein TAB2 (Aggarwal, 2003). The dimer of TAB2 and

251 TAK1 may then phosphorylate both Kenny/IKK $\beta$ and IRD5/IKK $\gamma /$ NEMO in a complex, and

252 JNK and Basket through MKK4 or MKK7/hemipterous (Hep) (Geuking et al., 2009). JNK may

253 activate Aop and the AP-1 complex of Jra/Jun and Fos/Kayak to regulate downstream genes (e.g.

254 PIRK). The IKK complex may phosphorylate the cleaved Relish to cause chain separation.

255 While the C-terminal ankrin repeats and death-like domain are destined to be degraded, the N-

256 terminal fragment (Relish-N), assisted by nuclear transport factor 2 (NTF2), could translocate

257 into the nucleus and activate expression of immunity-related genes (e.g. antimicrobial peptides)

258 via its Rel homology domain.

259 Additional regulatory mechanisms are known for the Imd pathway in Drosophila (Kleino and 260 Silverman, 2014). PIRK interferes with the association of Imd, FADD, and Dredd (Kleino et al., 261 2008). Dnr1 (defense repressor-1) inhibits the caspase Dredd while Sickie and Caspar have 262 opposite effects on Dredd-induced activation of Relish (Foley and O'Farrell, 2004). USP36 263 deubiquitinates Imd for its degradation and, thus, represses Imd signaling (Thevenon et al., 2009). 264 Another deubiquitinase, CYLD (for Cylindromatosis), modulates the IKK complex to control 
265 Relish phosphorylation (Tsichritzis et al., 2007). POSH controls the complex of TAK1 and 266 TAB2; an SCF complex of Skp1, Cullin and F-box protein regulates the phosphorylated Relish-

267 N; Akirin and Relish-N co-regulate some target genes of the Imd pathway (Tsuda et al., 2005;

268 Cardozo and Pagano, 2004; Bonnay et al., 2014).

269 Most genes in the putative Imd pathway are widely expressed in different tissues at various 270 life stages (Fig. 2B). The mRNA levels of Imd, FADD, Dredd, Relish, and many other genes are 271 considerably higher in midgut than in fat body. This is consistent with the finding that local 272 immune response of epithelial cells is Imd pathway-dependent, as the Imd pathway is fast and 273 can be activated within minutes following a challenge (Kleino and Silverman, 2014; Paquette et 274 al., 2010). While mRNA levels of a few genes are higher at $24 \mathrm{~h}$ after the immune challenge, 275 others are similar to or even lower than the control levels (Table 2). This contrasts drastically 276 with most of the Toll pathway genes, whose induced expression in fat body and hemocytes lasts 277 longer than $24 \mathrm{~h}$. Consistent with their immune inducibility, most Imd pathway members are 278 highly expressed in fat body from the pre-wandering larval stage to the early pupal stage (Fig. 279 2B). Their up-regulation in midgut is less pronounced and varies among the Imd pathway 280 members during the same period, perhaps due to gut purging.

MAPK pathways are responsive to growth factors, cytokines and stress signals, and thereby regulate cell proliferation, differentiation, inflammation, and death. In Drosophila, components 284 of these pathways activate MAPKs (Rolled, JNK and p38), down-regulate the Imd pathway, and 285 stimulate hemocyte proliferation and lamellocyte formation (Fig. 4C) (Ragab et al., 2011; Dong 286 et al., 2002; Lee and Ferrandon, 2011). We have identified homologs of two platelet-derived and 287 vascular endothelial growth factors (PVFs), a PDGF/VEGF receptor (PVR), two small GTPases 288 (Ras85D and Rac1), three kinases (Polehole, Dsor1 and Rolled), and a transcription factor 
289 (Pointed) that induces PIRK (poor Imd response upon knock-in) production. By interfering with 290 Imd-FADD-Dredd association, PIRK, a small protein with no known domain structure, may 291 inhibit Imd signaling. JNK may be activated through an Imd branch (Fig. 4B) and perhaps also 292 by MLK1, MKK4, PVR or Alk (PVR and Alk are receptors with a Ser/Thr kinase domain). We 293 have also found putative members of the cytokine-triggered MAPK pathway, namely Eiger, 294 Wengen, TRAF1, and Misshapen that may recruit and sequentially activate TAK1-TAB2 dimer, 295 MKK7/hemipterous, and JNK (Liu et al., 1999; Geuking et al., 2009). A protein called ECSIT 296 (evolutionarily conserved intermediate in Toll pathways) is linked to the Toll receptor through 297 TRAF2, and may activate a kinase cascade of MEKK1, MKK3, and p38 to induce the formation 298 of the AP-1 complex (Kopp et al., 1999). In addition, Spitz and Vein may induce MAPK 299 signaling in the presence of reactive oxygen species but their receptors are unknown in Manduca. 300 Certain members of the putative MAPK-JNK-p38 pathways (i.e. Eiger, Rac1, MASK, Rolled, 301 JNK, p38, Aop, Jra, Fos) in M. sexta are transcriptionally activated in larval fat body or 302 hemocytes after an immune challenge (Gunaratna and Jiang, 2013) (Table 2). In addition to these, PVF2, PVR, Wengen, Ras85D, Cdc42, Dsor1, Misshapen, MLK and Pointed show mRNA level 304 increases in fat body from pre-wandering to early pupal stage (Fig. 2C). Transcript levels for most of these genes in midgut are similar to or higher than those in fat body. Levels of PVR,

306 Rac1, Misshapen-B\&C, p38B, Ras85D, Jra and Fos mRNAs reach peak levels during pupation. 307 Expression of the pathway members in head, muscles, Malpighian tubules, testis, and ovary 308 clearly indicates that roles of the MAPK-JNK-p38 pathways are beyond immunity.

\subsubsection{JAK-STAT pathway and its regulation}

311 The JAK-STAT pathway is involved in antiviral immune responses in insects (Dostert et al., 312 2005; Kingsolver et al., 2013). In Drosophila, an extracellular protein, Unpaired3, binds to 
313 Domeless, causes receptor dimerization, and recruits STAM and Hopscotch/JAK, which in turn

314 phosphorylates itself and then STAT (Fig. 4D). We did not find an Unpaired3 ortholog in $M$.

315 sexta or T. castaneum (Zou et al., 2007). However, the $M$. sexta ortholog of Vago may bind to an

316 unknown receptor to activate JAK and STAT in a way similar to the unknown ligand of

317 Domeless. After phosphorylation, the STAT dimer translocates into the nucleus to induce

318 antiviral gene expression. SOCS (a JAK inhibitor) and PIAS (protein inhibitor of activated

319 STAT) may down-regulate the pathway. Except for the ligand, orthologs of all the pathway

320 components are present in $M$. sexta (Table 1). Domeless and SOCS mRNA levels increased 2.6-

321 fold in larval fat body at $24 \mathrm{~h}$ after the injection of a mixture of bacteria (Gunaratna and Jiang,

322 2013) (Table 2). We also found that their mRNA levels became more abundant in fat body and

323 midgut between wandering larval and early pupal stages (Fig. 2D). Similar increases were

324 observed for other members of the predicted pathway, including JAK, STAT and STAM.

325 3.6.2. RNA interference (RNAi) pathways

326 RNA interference plays important roles in limiting viral infection in insects (Kingsolver et al.,

327 2013; Fablet, 2014). There are three RNAi pathways (Fig. 4E): 1) small interfering RNAs

328 (siRNAs) are generated from double-stranded RNA (dsRNA) of viruses and siRNAs degrade or 329 inhibit viral RNA and thereby disrupt the viral infection cycle; 2) microRNAs (miRNAs) are 330 produced from cellular gene transcripts and typically function to control the translation or half331 life of their target transcripts, including those regulating immune responses; 3) Piwi-interacting 332 RNAs (piRNAs) provide epigenetic control of transposable elements and viral transcripts in 333 germ-line cells in order to prevent genome disruption. The siRNA pathway is mostly responsible 334 for antiviral activity in insects. Viral RNAs may form double stranded RNAs due to innate 335 secondary structures or via replication intermediate, and these dsRNAs are recognized and 336 cleaved by Dicer-2 to generate siRNAs, which are then loaded into RNA-induced silencing 
complexes consisting of Argonaute-2 and other proteins. Unwinding of the duplex occurs along with guide strand selection. After target RNA recognition by the guide RNA, the targeted viral RNA is degraded by Argonaute-2. We have identified 28 putative pathway members suggesting that these pathways are functional in $M . \operatorname{sexta}$ (Fig. 4E, Table 1). Since R2D2 is not found in $M$. sexta, we suggest that R3D1 (an ortholog of Drosophila Loquacious) acts as a Dicer-1 partner in the miRNA pathway, as well as a Dicer-2 partner in the siRNA pathway. Unlike Drosophila, which has distinct Piwi and Aubergine genes, lepidopteran insects have a single PIWI-clade protein that we refer to as Aub/Piwi. Transcript levels for members of the siRNA pathway are relatively higher than those for either piRNA or miRNA pathways (Fig. 2E), consistent with its greater role in antiviral immunity (Kingsolver et al., 2013). Expression profiles of these pathways do not exhibit fat body- and midgut-specific up-regulation from wandering to early pupal stage, except for Dicer-2 and Argonaute-2. The Argonaute-2 mRNA levels increased moderately in induced fat body and hemocytes (Table 2). Although transcript abundances for piRNA pathway components vary, they are almost always higher in testis and ovary than the other tissues, consistent with their roles in the germline cells.

\subsubsection{Autophagy}

Autophagy is a cellular process in which dysfunctional or unnecessary cellular materials or components are selectively targeted, then separated from the cytoplasm in double membrane vesicles (autophagosomes), and ultimately degraded by lysosomes (Mulakkal et al., 2014). Some pathogens may also be targeted to autophagosomes. Autophagy recycles the cellular materials and maintains cellular homeostasis under a variety of conditions. It is implicated in cellular responses to stress by nutrient-restriction, developmental changes involving tissue reorganization during metamorphosis, and certain pathological processes. The signaling of autophagy is mediated through the phosphoinositide 3-kinase (PI3K)-Akt pathway (Fig. 4F), which 
361 phosphorylates TOR to suppress autophagy. Autophagy itself involves about 20 components

362 conserved throughout eukaryotes from yeast to mammals. In Drosophila, autophagy is induced

363 upon infection by some viruses, intracellular bacteria (e.g. Listeria monocytogenes), and other

364 pathogens (Yano et al., 2008; Kingsolver et al., 2013), suggesting that in addition to other

365 cellular functions, it may also serve as an ancient cellular immune response. We have identified

366 orthologs of all known autophagy pathway members (Fig. 4F, Table 1) and examined their

367 expression profiles (Fig. 2F). As components of a ubiquitination complex, Atg3, 4, 5, 7, 8, 10, 12

368 and 16 are highly expressed in all the tissue samples used for RNA-Seq analyses. The mRNA

369 levels of these autophagy pathway genes are generally higher in midgut than in fat body, testis

370 and ovary. Since there is no major increase in mRNA levels in the pupal stage, autophagy may

371 be partly supported by pre-existing proteins. Transcript levels of Atg2 through 6, 8, 9, and 16 are

372 up-regulated in fat body and midgut from wandering larvae and young pupae, and decrease in the

373 later stages. These changes may correlate with cellular reorganization in cells undergoing

374 metamorphosis. In contrast, the PI3K, Akt, TOR, Vps34, Atg1, 7, 10, 12, 13, 17, 18, and 101

375 mRNA levels remain high from pupal to adult stage. Based on our current data (Fig. 2F),

376 expression of autophagy-related genes appears to be a development-regulated process. There is

377 no strong correlation with their immune inducibility, perhaps due to the fact we did not use

378 viruses or intracellular bacteria to challenge the larvae.

379 3.6.4. Apoptosis

380 Apoptosis, the best characterized mechanism of programmed cell death, is a part of normal 381 developmental processes such as tissue modeling and homeostasis, but apoptosis can also 382 participate in pathological processes including cancer and defense against pathogens (Opferman 383 and Korsmeyer, 2003). In Drosophila, the initiator caspase Dronc and an adaptor protein (Ark) 384 form a large protein complex (apoptosome) in response to intrinsic signals (Hay and Guo, 2006). 
It is not clear how the other Drosophila initiator caspases, Dredd and Strica, are activated. Once Dronc is activated, it cleaves and activates effector caspases such as Drice and Dcp1 to cleave other protein substrates that lead to the downstream events of programmed cell death. Negative regulators of caspases (e.g. IAPs, Dnr1) control the pathway by inhibiting the activation of initiator caspases through either direct binding or by ubiquitination-induced degradation (Orme and Meier, 2009). Likewise, IAP antagonists (e.g. Reaper, Hid, Grim and Sickle) inactivate IAPs and, thus induce apoptosis. We have identified 12 members of the core apoptosis pathway in $M$. sexta, including Reaper, IAP1, IAP2, Deterin/IAP3, Dnr1, Ark, Dredd/caspase-6, Dronc/caspase5, caspase-1, -3, and -4 (Fig. 4G) (Courtiade et al., 2011). While Dnr1, Dredd, and IAP2 are likely involved in the balance between the Imd and apoptosis pathways, the other proteins may be devoted to programmed cell death. Reaper, an indirect pathway activator, is produced in the embryo, pupal fat body and midgut, as well as adult head, Malpighian tubules, testis and ovary (Fig. 2G), suggesting a possible role of apoptosis in tissue remodeling. The IAP3 mRNA, which is related to Survivin, a mitotic spindle-associated protein, is strikingly high and may perhaps regulate embryonic development. With a similar expression profile, IAP1 may block caspase-3 and -4 in cells of midgut, fat body, and other tissues. The high transcript abundances in midgut of feeding and wandering larvae, pupae and adults could indicate that the tissue is poised to undergo or carefully regulate active programmed cell death and regeneration. In addition, the caspase-1 and IAP1 mRNA peaks in fat body and midgut from wandering to early pupal stage correlate with their immune inducibility (Table 2).

\subsection{Concluding remarks}

Our search of the $M$. sexta genome has yielded 187 genes encoding 198 putative members of the immunity-related signal transduction pathways, namely Toll, Imd, MAPK-JNK-p38, JAKSTAT, piRNA, siRNA, miRNA, autophagy and apoptosis. Analysis of the expression profiles 

414 cellular biological methods.

415

416

417

418

419

420

421

422

423

\section{Acknowledgements}

\section{References}

reveals differences among the proposed pathways (e.g. Toll, Imd, and MAPK-JNK-p38) and among some of the components (e.g. Spätzles, Tolls). These results suggest that the intracellular signaling system is functional in this undomesticated insect, and thus pave the way for understanding and potentially modulating similar pathways in pest lepidopteran species. The proposed signaling network needs experimental validation using biochemical, molecular and

This work was supported by NIH grants GM58634 (to H. Jiang) and a DARPA/NSF (IOS1354421) grants (to G. Blissard). Computation for this project was performed at OSU High Performance Computing Center at Oklahoma State University supported in part through NSF grant OCI-1126330. This work was approved for publication by the Director of Oklahoma Agricultural Experimental Station, and supported in part under project OKLO2450.

Aggarwal, B.B., 2003. Signalling pathways of the TNF superfamily: a double-edged sword. Nat Rev Immunol. 3, 745-756.

Altincicek B, Vilcinskas A., 2008. Identification of a lepidopteran matrix metalloproteinase with dual roles in metamorphosis and innate immunity. Dev Comp Immunol. 32, 400-409.

An, C., Jiang, H., Kanost, M.R., 2010. Proteolytic activation and function of the cytokine Spätzle in the innate immune response of a lepidopteran insect, Manduca sexta. FEBS J. 277, 148162.

Anjum, S.G., Xu, W., Nikkholgh, N., Basu, S., Nie, Y., 2013. Regulation of Toll signaling and inflammation by $\beta$-arrestin and the SUMO protease Ulp1. Genetics. 195, 1307-1317.

Ao, J.-Q., Ling, E., Rao, X.J., Yu, X.Q., 2008a. A novel ML protein from Manduca sexta may function as a key accessory protein for lipopolysaccharide signaling. Mol Immunol. 45, $2772-2781$.

Ao, J.-Q., Ling, E., Yu, X.-Q., 2008b. A Toll receptor from Manduca sexta is in response to Escherichia coli infection. Mol Immunol. 45, 543-552.

Avila, A., Silverman, N., Diaz-Meco, M.T., Moscat, J., 2002. The Drosophila atypical protein 
kinase C-ref(2)p complex constitutes a conserved module for signaling in the toll pathway. Mol Cell Biol. 22, 8787-8795.

Baeg, G.H., Zhou, R., Perrimon, N., 2005. Genome-wide RNAi analysis of JAK/STAT signaling components in Drosophila. Genes Dev. 19, 1861-1870.

Ballard, S.L., Miller, D.L., Ganetzky, B., 2014. Retrograde neurotrophin signaling through Tollo regulates synaptic growth in Drosophila. J Cell Biol. 204, 1157-1172.

Bhaskar, V., Smith, M., Courey, A.J., 2002. Conjugation of Smt3 to Dorsal may potentiate the Drosophila immune response. Mol Cell Biol. 22, 492-504.

Bonnay, F., Nguyen, X.H., Cohen-Berros, E., Troxler, L., Batsche, E., Camonis, J., Takeuchi, O., Reichhart, J.M., Matt, N., 2014. Akirin specifies NF-кB selectivity of Drosophila innate immune response via chromatin remodeling. EMBO J. 33, 2349-2362.

Buchon, N., Silverman, N., Cherry, S., 2014. Immunity in Drosophila melanogaster - from microbial recognition to whole-organism physiology. Nat Rev Immunol. 14, 796-810.

Cao, X., He, Y., Hu, Y., Zhang, X., Wang, Y., Zou, Z., Chen, Y., Blissard, G., Kanost, M.R., Jiang, H., 2015. Sequence conservation, phylogenetic relationships, and expression profiles of nondigestive serine proteases and serine protease homologs in Manduca sexta. Insect Biochem Mol Biol. in press.

Cao, X., Jiang, H., 2015. Integrated modeling of protein-coding genes in the Manduca sexta genome using RNA-Seq data from the biochemical model insect. Insect Biochem. Mol. Biol. in press.

Cardozo, T., Pagano, M., 2004. The SCF ubiquitin ligase: insights into a molecular machine. Nat Rev Mol Cell Biol. 5, 739-751.

Chen, J., Xie, C., Tian, L., Hong, L., Wu, X., Han, J., 2010. Participation of the p38 pathway in Drosophila host defense against pathogenic bacteria and fungi. Proc Natl Acad Sci USA. 107, 20774-20779.

Chiu, H., Ring, B.C., Sorrentino, R.P., Kalamarz, M., Garza, D., Govind, S., 2005. dUbc9 negatively regulates the Toll-NF-kappa B pathways in larval hematopoiesis and drosomycin activation in Drosophila. Dev Biol. 288, 60-72.

Courtiade, J., Pauchet, Y., Vogel, H., Heckel, D.G., 2011. A comprehensive characterization of the caspase gene family in insects from the order Lepidoptera. BMC Genomics. 12, 357.

Dong, C., Davis, R.J., Flavell, R.A., 2002. MAP kinases in the immune response. Ann Rev Immunol. 20, 55-72.

Dong, Y., Aguilar, R., Xi, Z., Warr, E., Mongin, E., Dimopoulos, G., 2006. Anopheles gambiae immune responses to human and rodent Plasmodium parasite species. PLoS Pathog. 2, e52.

Dostert, C., Jouanguy, E., Irving, P., Troxler, L., Galiana-Arnoux, D., Hetru, C., Hoffmann, J.A., Imler, J.-L., 2005. The JAK-STAT signaling pathway is required but not sufficient for the antiviral response of Drosophila. Nat Immunol. 6, 946-953.

Ertürk-Hasdemir, D., Broemer, M., Leulier, F., Lane, W.S., Paquette, N., Hwang, D., Kim, C.H., Stöven, S., Meier, P., Silverman, N., 2009. Two roles for the Drosophila IKK complex in the activation of Relish and the induction of antimicrobial peptide genes. Proc Natl Acad Sci USA 106, 9779-9784. 
Evans, J.D., Aronstein, K., Chen, Y.P., Hetru, C., Imler, J.L., Jiang, H., Kanost, M., Thompson, G.J., Zou, Z., Hultmark, D., 2006. Immune pathways and defence mechanisms in honey bees Apis mellifera. Insect Mol Biol. 15, 645-656.

Fablet, M., 2014. Host control of insect endogenous retroviruses: small RNA silencing and immune response. Viruses. 6, 4447-4464.

Foley, E., O'Farrell, P.H., 2004. Functional dissection of an innate immune response by a genome-wide RNAi screen. PLoS Biol. 2, e203.

Gerardo, N.M., Altincicek, B., Anselme, C., Atamian, H., Barribeau, S.M., de Vos M., Duncan, E.J., Evans, J.D., Gabaldón, T., Ghanim, M., Heddi, A., Kaloshian, I., Latorre, A., Moya, A., Nakabachi, A., Parker, B.J., Pérez-Brocal, V., Pignatelli, M., Rahbé, Y., Ramsey, J.S., Spragg, C.J., Tamames, J., Tamarit, D., Tamborindeguy, C., Vincent-Monegat, C., Vilcinskas, A., 2010. Immunity and other defenses in pea aphids, Acyrthosiphon pisum. Genome Biol. 11, R21

Geuking, P., Narasimamurthy, R., Lemaitre, B., Basler, K., Leulier, F., 2009. A non-redundant role for Drosophila MKK4 and hemipterous/MKK7 in TAK1-mediated activation of JNK. PLoS One. 4, e7709.

Gillespie, J.P., Kanost, M.R., Trenczek, T., 1997. Biological mediators of insect immunity. Ann Rev Entomol 42, 611-643.

Gunaratna, R.T., Jiang, H., 2013. A comprehensive analysis of the Manduca sexta immunotranscriptome. Dev Comp Immunol. 39, 388-398.

Han, S.J., Choi, K.Y., Brey, P.T., Lee, W.J., 1998. Molecular cloning and characterization of a Drosophila p38 mitogen-activated protein kinase. J Biol Chem. 273, 369-374.

Hay, B.A., Guo, M., 2006. Caspase-dependent cell death in Drosophila. Ann Rev Cell Dev Biol. $22,623-650$.

He, Y., Cao, X., Li, K., Hu, Y., Chen, Y., Blissard, G., Kanost, M.R., Jiang, H., 2015. A genome-wide analysis of antimicrobial effector genes and their transcription patterns in Manduca sexta. Insect Biochem Mol Biol. in press

Hou, X.S., Perrimon, N., 1997. The JAK-STAT pathway in Drosophila. Trends Genet. 13, 105110.

Imler, J.L., Hoffmann, J.A., 2001. Toll receptors in innate immunity. Trends Cell Biol. 11, 304 311.

Jiang, H., Vilcinskas, A., Kanost, M.R., 2010. Immunity in lepidopteran insects. Adv Exp Med Biol. 708, 181-204.

Kaneko, T., Yano, T., Aggarwal, K., Lim, J.-H., Ueda, K., Oshima, Y., Peach, C., ErturkHasdemir, D., Goldman, W.E., Oh, B.-H., 2006. PGRP-LC and PGRP-LE have essential yet distinct functions in the Drosophila immune response to monomeric DAP-type peptidoglycan. Nat Immunol. 7, 715-723.

Kingsolver, M.B., Huang, Z., Hardy, R.W., 2013. Insect antiviral innate immunity: pathways, effectors, and connections. J Mol Biol. 425, 4921-4936.

Kisseleva, T., Bhattacharya, S., Braunstein, J., Schindler, C.W., 2002. Signaling through the JAK/STAT pathway, recent advances and future challenges. Gene 285, 1-24. 
Kleino, A., Myllymäki, H., Kallio, J., Vanha-aho, L.M., Oksanen, K., Ulvila, J., Hultmark, D., Valanne, S., Rämet, M., 2008. Pirk is a negative regulator of the Drosophila Imd pathway. J Immunol. 180, 5413-5422.

Kleino, A., Silverman, N., 2014. The Drosophila Imd pathway in the activation of the humoral immune response. Dev Comp Immunol. 42, 25-35.

Kopp, E., Medzhitov, R., Carothers, J., Xiao, C., 1999. ECSIT is an evolutionarily conserved intermediate in the Toll/IL-1 signal transduction pathway. Genes Dev. 13, 2059-2071.

Kristensen, N.P., Scoble, M.J., Karsholt, O., 2007. Lepidoptera phylogeny and systematics: the state of inventorying moth and butterfly diversity. Zootaxa 1668, 699-747.

Langmead, B., Trapnell, C., Pop, M., Salzberg, S.L., 2009. Ultrafast and memory-efficient alignment of short DNA sequences to the human genome. Genome Biol. 10, R25.

Lee, K.Z., Ferrandon, D., 2011. Negative regulation of immune responses on the fly. EMBO J. 30, 988-990

Lemaitre, B., Hoffmann, J., 2007. The host defense of Drosophila melanogaster. Ann Rev Immunol 25, 697-743.

Li, B., Dewey, C., 2011. RSEM: accurate transcript quantification from RNA-Seq data with or without a reference genome. BMC bioinformatics 12, 323.

Lin, P., Huang, L.H., Steward, R., 2000. Cactin, a conserved protein that interacts with the Drosophila IкB protein cactus and modulates its function. Mech Dev. 94, 57-65.

Liu, H., Su, Y.C., Becker, E., Treisman, J., Skolnik, E.Y., 1999. A Drosophila TNF-receptorassociated factor (TRAF) binds the Ste20 kinase Misshapen and activates Jun kinase. Curr Biol. 9, 101-104.

McIlroy, G., Foldi, I., Aurikko, J., Wentzell, J.S., Lim, M.A., Fenton, J.C., Gay, N.J., Hidalgo, A., 2013. Toll-6 and Toll-7 function as neurotrophin receptors in the Drosophila melanogaster CNS. Nat Neurosci. 16, 1248-1256.

Mellroth, P., Karlsson, J., Håkansson, J., 2005. Ligand-induced dimerization of Drosophila peptidoglycan recognition proteins in vitro. Proc Natl Acad Sci USA. 102, 6455-6460.

Mulakkal, N.C., Nagy, P., Takats, S., Tusco, R., Juhász, G., Nezis, I.P., 2014. Autophagy in Drosophila: from historical studies to current knowledge. BioMed Res Int. 2014, 273473,

Nakamoto, M., Moy, R.H., Xu, J., Bambina, S., Yasunaga, A., Shelly, S.S., Gold, B., Cherry, S., 2012. Virus recognition by Toll-7 activates antiviral autophagy in Drosophila. Immunity 36, $658-667$.

Opferman, J.T., Korsmeyer, S.J., 2003. Apoptosis in the development and maintenance of the immune system. Nat Immunol. 4, 410-415.

Orme, M., Meier, P., 2009. Inhibitor of apoptosis proteins in Drosophila: gatekeepers of death. Apoptosis 14, 950-960

Paddibhatla, I., Lee, M.J., Kalamarz, M.E., Ferrarese, R., Govind, S., 2010. Role for sumoylation in systemic inflammation and immune homeostasis in Drosophila larvae. PLoS Pathog. 6, e1001234.

Paquette, N., Broemer, M., Aggarwal, K., Chen, L., Husson, M., Ertürk-Hasdemir, D., Reichhart, J.M., Meier, P., Silverman, N., 2010. Caspase-mediated cleavage, IAP binding, and 


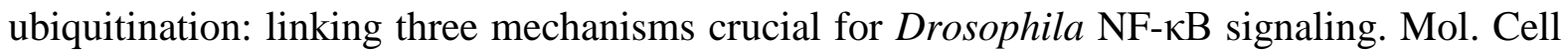
$37,172-182$.

Petersen, T., Brunak, S., von Heijne, G., Nielsen, H., 2011. SignalP 4.0: discriminating signal peptides from transmembrane regions. Nat Methods. 8, 785-786.

Ragab, A., Buechling, T., Gesellchen, V., Spirohn, K., Boettcher, A.L., Boutros, M., 2011. Drosophila Ras/MAPK signalling regulates innate immune responses in immune and intestinal stem cells. EMBO J. 30, 1123-1136.

Rämet, M., Manfruelli, P., Pearson, A., Mathey-Prevot, B., Ezekowitz, R.A., 2002. Functional genomic analysis of phagocytosis and identification of a Drosophila receptor for E. coli. Nature. 416, 644-648.

Rao, X-J., Cao, X., He, Y., Hu, Y., Zhang, X., Chen, Y., Blissard, G., Kanost, M.R., Yu, X-Q., Jiang, H., 2015. Structural features, evolutionary relationships, and transcriptional regulation of C-type lectin-domain proteins in Manduca sexta. Insect Biochem Mol Biol. in press.

Rao, X-J., Xu, X-X., Yu, X-Q., 2011. Manduca sexta moricin promoter elements can increase promoter activities of Drosophila melanogaster antimicrobial peptide genes. Insect Biochem Mol Biol. 41, 982-992.

Sorrentino, R.P., Melk, J.P., Govind, S., 2004. Genetic analysis of contributions of dorsal group and JAK-Stat92E pathway genes to larval hemocyte concentration and the egg encapsulation response in Drosophila. Genetics 166, 1343-1356

Strand, M.R., 2008. The insect cellular immune response. Insect Sci. 15, 1-15.

Tamura, K., Stecher, G., Peterson, D., Filipski, A., Kumar, S., 2013. MEGA6: molecular evolutionary genetics analysis version 6.0. Mol Biol Evo. 30, 2725-2729.

Tanaka, H., Ishibashi, J., Fujita, K., Nakajima, Y., Sagisaka, A., Tomimoto, K., Suzuki, N., Yoshiyama, M., Kaneko, Y., Iwasaki, T., Sunagawa, T., Yamaji, K., Asaoka, A., Mita, K., Yamakawa, M., 2008. A genome-wide analysis of genes and gene families involved in innate immunity of Bombyx mori. Insect Biochem Mol Biol. 38, 1087-1110.

Thevenon, D., Engel, E., Avet-Rochex, A., Gottar, M., Bergeret, E., Tricoire, H., Benaud, C., Baudier, J., Taillebourg, E., Fauvarque, M.O., 2009. The Drosophila ubiquitinspecific protease dUSP36/Scny targets Imd to prevent constitutive immune signaling. Cell Host Microbe 6, 309-320.

Tsichritzis, T., Gaentzsch, P.C., Kosmidis, S., Brown, A.E., Skoulakis, E.M., Ligoxygakis, P., Mosialos, G., 2007. A Drosophila ortholog of the human cylindromatosis tumor suppressor gene regulates triglyceride content and antibacterial defense. Development 134, 2605-2614.

Tsuda, M., Langmann, C., Harden, N., Aigaki, T., 2005. The RING-finger scaffold protein Plenty of SH3s targets TAK1 to control immunity signaling in Drosophila. EMBO Rep. 6, 1082-1087.

Valanne, S., Wang, J.H., Rämet, M., 2011. The Drosophila Toll signaling pathway. J Immunol. $186,649-656$.

Vilcinskas, A., 2013. Evolutionary plasticity of insect immunity. J Insect Physiol. 59, 123-129.

Yano, T., Mita, S., Ohmori, H., Oshima, Y., Fujimoto, Y., Ueda, R., Takada, H., Goldman, W.E., Fukase, K., Silverman, N., Yoshimori, T., Kurata, S., 2008. Autophagic control of Listeria 
through intracellular innate immune recognition in Drosophila, Nat Immunol. 9, 908916.

Zhang, G., Ghosh, S., 2002. Negative regulation of toll-like receptor-mediated signaling by Tollip. J Biol Chem. 277, 7059-7065.

Zhang, S., Gunaratna, R., Zhang, X., Najar, F., Wang, Y., Roe, B., Jiang, H., 2011.

Pyrosequencing-based expression profiling and identification of differentially regulated genes from Manduca sexta, a lepidopteran model insect. Insect Biochem Mol Biol. 41, 733746.

Zhang, X., He, Y., Cao, X., Gunaratna, R.T., Chen, Y., Blissard, G.W., Kanost, M.R., Jiang, H., 2015. Phylogenetic analysis and expression profiling of the pattern recognition receptors: insights into molecular recognition of invading pathogens in Manduca sexta. Insect Biochem. Mol. Biol. in review

Zhang, X., Zheng, Y., Jagadeeswaran, G., Ren, R., Sunkar R., Jiang, H., 2014. Identification of conserved and novel microRNAs in Manduca sexta and their possible roles in the expression regulation of immunity-related genes. Insect Biochem Mol Biol. 47, 12-22.

Table 1. A list of predicted members of the intracellular immune signaling pathways in M. sexta. (see attached Excel file)

Table 2. Relative mRNA abundances of the intracellular signaling pathway members in induced (I) and control (C) fat body (F) and hemocytes from the larvae of M. sexta.

\begin{tabular}{|c|c|c|c|c|c|c|c|c|c|c|c|}
\hline Name & $\mathrm{IF} / \mathrm{CF}$ & $\mathrm{IH} / \mathrm{CH}$ & Name & $\mathrm{IF} / \mathrm{CF}$ & $\mathrm{IH} / \mathrm{CH}$ & Name & $\mathrm{IF} / \mathrm{CF}$ & $\mathrm{IH} / \mathrm{CH}$ & Name & $\mathrm{IF} / \mathrm{CF}$ & $\mathrm{IH} / \mathrm{CH}$ \\
\hline Spätzle1* & 1.4 & 3.9 & Dredd* & 1.8 & 1.2 & MLK1* & 1 & 2.1 & R3D1/Loqs & 0.8 & 1.3 \\
\hline Spätzle2 & 1.5 & 2.2 & Relish* & 5.2 & 1.5 & MKK4* & 0.8 & 0.5 & Dicer1 & 0 & 0.7 \\
\hline Spätzle7 & 4.1 & 3.6 & NTF2* & 1.2 & 1.7 & $\mathrm{JNK}^{*}$ & 1.8 & 1.6 & Ago1 & 1 & 2.6 \\
\hline Toll1* & 2.5 & 6.2 & TAK1* & 0.5 & 3.6 & Basket & 1.3 & 2.7 & Drosha & 1.3 & 1.1 \\
\hline Toll2 & 0.7 & 0.8 & Tab2* & 2.5 & 1 & ECSIT* & 1 & 1.7 & Pasha & - & 1.5 \\
\hline Toll3 & 2.5 & 6.2 & IKK $\beta *$ & 0.5 & 0.2 & MEKK1* & 0 & 0.6 & Expotin5 & 4.1 & 1.7 \\
\hline Toll4 & 2.5 & 6.4 & IKK $\gamma^{*}$ & 2.5 & 1.2 & MKK3* & 1.4 & 1.1 & Nibbler & 0.7 & 1.4 \\
\hline Toll5 & 2.9 & 0.9 & NEMO & 1 & 1.2 & p38* & 2.2 & 1 & Gawky & 0.9 & 0.9 \\
\hline ML1 & 2.2 & 0.6 & Dnr1 & 2.2 & 0.5 & Aop* & 3.1 & 1.2 & Мe31B & 1 & 0.8 \\
\hline ML2 & 1.8 & 0.8 & Sickie* & 1 & 33.2 & FOS* & 2 & 1.9 & Ge-1 & 0.5 & 1 \\
\hline MyD88* & 1.5 & 1.5 & Caspar* & 3.1 & 1.6 & Jra* & 1.6 & 0.9 & Atg1 & 2.8 & 0.9 \\
\hline Tube* & 8.4 & 0.8 & IAP2* & 0.3 & 0.9 & Ebi & 1 & 1.4 & Atg13 & 0.4 & 1.3 \\
\hline Pelle* & 5.1 & 2.2 & Bendless* & 1.2 & 2.1 & Smrter & 1.8 & 1.2 & Atg101 & 1.3 & 0.6 \\
\hline Pellino* & 2.3 & 1.3 & Uev1A* & 1.4 & 1.1 & Rpd3/HDAC1 & 0.2 & 1.2 & Atg17 & 0.6 & 0.7 \\
\hline Cactus* & 9.2 & 1.8 & Effete & 0.8 & 1.1 & Domeless* & 2.4 & 0.8 & Vps34 & 0.5 & 1.2 \\
\hline Dorsal* & 1.3 & 1.2 & USP36 & 0.5 & 1.4 & Stam* & 2 & 1.1 & Vps15 & 0.5 & 1.6 \\
\hline Tollip-1* & 1 & - & POSH1* & 1.7 & 0.9 & JAK/Hopscotch* & 1 & 0.5 & Atg6 & 0.5 & 1.2 \\
\hline Tollip-2* & 0.8 & 1.1 & $\mathrm{POSH} 2$ & 0.8 & 1.3 & STAT* & 0.4 & 0.7 & Atg18 & 3.6 & 0.8 \\
\hline Ref2P* & 1.5 & 1 & CYLD & 3.6 & 0.8 & PIAS* & 1.6 & 1 & Atg12 & 0.5 & 3 \\
\hline aPKC* & - & 1 & SkpA & 0.5 & 1.7 & SOCS* & 2.5 & 0.8 & Atg7 & 0.5 & 0.5 \\
\hline GPRK2 & 0.1 & 0.7 & Cullin & 0.9 & 1.3 & ZHF1 & 0.7 & 1 & Atg5 & 0.5 & 1 \\
\hline Cactin & 0.5 & 2.5 & SlimB & 1.5 & 0.7 & Piwi & 0.4 & 0.8 & Atg 4 & 0.2 & 1.1 \\
\hline Aos1* & 0.7 & 1.7 & Akirin & 9.2 & 1.7 & Armitage & 1.4 & 1 & Atg8 & 3.1 & 0.6 \\
\hline Uba2* & 2.5 & 1.5 & Dsp & 2 & 1.4 & $\mathrm{Yb}$ & 0.5 & 0.2 & Atg3 & 0.3 & 1 \\
\hline Lesswright* & 4.6 & 1.2 & Eiger* & 0.8 & 8 & Shu & 0.5 & 5.9 & Atg2 & 1.2 & 0.2 \\
\hline Ulp1 & 5.6 & 0.8 & PVR* & 1 & 1.4 & Qin & 0.7 & 0.9 & Atg9 & 1.5 & 0.9 \\
\hline Kurtz & 1 & 0.7 & Ras85D* & 0.7 & 1.7 & Dicer2 & 1.3 & 1.5 & Akt & 1 & 1 \\
\hline Smt3* & 1.6 & 1.6 & Rac1* & 2.5 & 1.3 & Ago2 & 0.8 & 1 & TOR & 0.2 & 0.8 \\
\hline Deaf1 & - & 0.9 & $\operatorname{Cdc} 42^{*}$ & 1.3 & 1.4 & Vig & 0.9 & 1.1 & $\mathrm{PI3K}$ & 1.5 & 0.9 \\
\hline Serpent* & 0.4 & 0.9 & MASK* & 1.2 & 1.4 & TSN & 0.6 & 1.2 & IAP1 & 1.6 & 1.1 \\
\hline Pannier-1 & 0.5 & 2.4 & Polehole & 0.5 & 1 & Ars2 & 3.1 & 1.7 & Deterin & - & 0.7 \\
\hline Pannier-2 & 1 & 2.4 & Dsor1* & 0.5 & 1.1 & $\mathrm{CBC}$ & - & 3.1 & Dronc & 0.5 & 1.2 \\
\hline
\end{tabular}




\begin{tabular}{|c|c|c|c|c|c|c|c|c|c|c|c|}
\hline GATAe & 0.5 & 2.4 & Rolled & 1.9 & 1.1 & Belle/Cap & 1.2 & 1.5 & Ark & 2 & 0.6 \\
\hline U-shaped & 0.3 & 1.1 & Pointed & 0.3 & 0.9 & Blanks & 2.5 & 1.1 & Caspase-1 & 1.5 & 1.4 \\
\hline Imd* & 2.7 & 1 & Misshapen* & 1.6 & 0.8 & Translin & 0.5 & 0.9 & & & \\
\hline FADD* & 0.6 & 1.3 & Hep/MKK7* & 1.5 & 1.2 & Tis11 & 1.3 & 0.9 & & & \\
\hline
\end{tabular}

As described in Section 2.3, the transcriptome data of larval fat body and hemocytes before and after the immune challenge (Zhang et al., 2011) were processed again according to Gunaratna and Jiang (2013), based on the BLAST search using 196 complete coding sequences as queries. The ones with no hit in the CIFH library are omitted from the table. Note that, due to the increase in query sizes and contig hits, the reported relative abundances (*) (i.e. IF/IH and CF/CH) (Gunaratna and Jiang, 2013) may be different for certain genes. "_": C and I = 0

\section{Figure legends}

426 Fig. 1. Phylogenetic relationships of Spätzles in M. sexta, B. mori, T. castaneum, and D. 427 melanogaster. (A) Tree. Based on the sequence alignment of 29 full-length Spätzles, a tree was generated with branches shown in colors representing closely related groups. (B) Aligned sequences of the cystine-knot cytokine domains in $M$. sexta Spätzles-1 through 7. Cys residues are indicated in a red font. Some Cys residues may form intra- (1-1, 2-2, 3-3) and inter- (4) chain disulfide bonds. Proteolytic activation sites, known for Spätzle-1, are predicted to be next to the Arg (red) in Spätzle-2 through 6. The putative processing site (RXXR) is underlined in Spätzle-3

433 and 5.

Fig. 2. Transcript profiles of the putative signaling protein genes in the 52 tissue samples. The mRNA levels, as represented by $\log _{2}(\mathrm{FPKM}+1)$ values, are shown in the gradient heat map from blue $(0)$ to red $(\geqslant 10)$. The values of $0-0.49,0.50-1.49,1.50-2.49 \cdots 8.50-9.49,9.50-10.49$

439 libraries are constructed from the following tissues and stages: head [ $2^{\text {nd }}$ (instar) L (larvae), d1 440 (day 1 ) $; 3^{\text {rd }} \mathrm{L}, \mathrm{d} 1 ; 4^{\text {th }} \mathrm{L}, \mathrm{d} 0.5 ; 4^{\text {th }} \mathrm{L}$, late $; 5^{\text {th }} \mathrm{L}, \mathrm{d} 0.5 ; 5^{\text {th }} \mathrm{L}, \mathrm{d} 2 ; 5^{\text {th }} \mathrm{L}$, pre-W (pre-wandering); P 441 (pupae), late; A (adults), d1; A, d3; A, d7], fat body ( $4^{\text {th }} \mathrm{L}$, late; $5^{\text {th }} \mathrm{L}, \mathrm{d} 1 ; 5^{\text {th }} \mathrm{L}$, pre-W; $5^{\text {th }} \mathrm{L}, \mathrm{W}$; P, d1-3; P, d15-18; A, d1-3; A, d7-9), whole animals [E (embryos), 3h; E, late; $1^{\text {st }} \mathrm{L} ; 2^{\text {nd }} \mathrm{L} ; 3^{\text {rd }} \mathrm{L}$ ), 
443 midgut $\left(2^{\text {nd }} \mathrm{L} ; 3^{\text {rd }} \mathrm{L} ; 4^{\text {th }} \mathrm{L}, 12 \mathrm{~h} ; 4^{\text {th }} \mathrm{L}\right.$, late $; 5^{\text {th }} \mathrm{L}, 1-3 \mathrm{~h} ; 5^{\text {th }} \mathrm{L}, 24 \mathrm{~h} ; 5^{\text {th }} \mathrm{L}$, pre-W; $5^{\text {th }} \mathrm{L}, \mathrm{W} ; \mathrm{P}, \mathrm{d} 1 ; \mathrm{P}$, 444 d15-18; A, d3-5; $\left.4^{\text {th }} \mathrm{L}, 0 \mathrm{~h}\right)$, Malpighian tubules $(\mathrm{MT})\left(5^{\text {th }} \mathrm{L}\right.$, pre-W; A, d1; A, d3), muscle $\left(4^{\text {th }} \mathrm{L}\right.$,

445 late; $5^{\text {th }} \mathrm{L}, 12 \mathrm{~h} ; 5^{\text {th }} \mathrm{L}$, pre-W; $\left.5^{\text {th }} \mathrm{L}, \mathrm{W}\right)$, testis $(\mathrm{P}, \mathrm{d} 3 ; \mathrm{P}, \mathrm{d} 15-18 ; \mathrm{A}, \mathrm{d} 1-3)$, and ovary $(\mathrm{P}, \mathrm{d} 15-18$;

446 A, d1). Some libraries (underlined) are from single-end sequencing; the others are from paired-

447 end sequencing. Note that some synonymous libraries exhibit different FPKMs due to method

448 differences. Panel A, Toll; B, Imd with JNK branch; C, MAPK-JNK-p38; D, JAK-STAT; E, pi-

449 si- and mi-RNA pathways, F, autophagy; G, apoptosis.

450

451 Fig. 3. Domain structures (A), phylogenetic relationships (B), and gene orders (C) of Tolls in $M$.

452 sexta. (A) Signal peptide (SP), Leu-rich repeat (LRR), amino- and carboxyl-terminal (NT \& CT)

453 LRRs, low complexity (LC) region, transmembrane (TM) segment, and TIR (Toll/interleukin-1

454 receptor) domain are shown in different colors and shapes as indicated. (B) Amino acid 455 sequences of the 58 full-length Toll proteins from M. sexta, B. mori, T. castaneum, A. gambiae, 456 and D. melanogaster are aligned to generate the tree with its branches in different colors for 457 closely related groups. (C) Orientations and orders of the Toll genes in the five insects are 458 schematically shown as arrows in the same colors as in panel B. Arrows for the single exon 459 genes are in black frame.

460

461 Fig. 4. Putative signaling pathways and regulators for antimicrobial immune responses in $M$. 462 sexta. Panels A, Toll; B, Imd with JNK branch; C, MAPK-JNK-p38; D, JAK-STAT; E, pi- si463 and mi-RNA pathways, F, autophagy; G, apoptosis. Panels A through $\mathrm{G}$ are described in the text. 


\begin{tabular}{|c|c|c|c|c|}
\hline Gene name & \multirow[t]{2}{*}{ note } & AA sequence & length & Domains \\
\hline Toll pathway & & & & \\
\hline Spz1A & & MAWIQHLLVWIATGGCCTG & 295 & \\
\hline Spz1B & & MAWIQHLLVWIATGGCCTG & 305 & \\
\hline Spz2 & & MYRGLFVILAIG( ATGTATCG & 206 & \\
\hline Spz3 & & MALTNFTLAAV ( ATGGCTTTI & 503 & \\
\hline Spz4 & & MLYAIAFIFVTTV ATGCTCTAI & 472 & \\
\hline Spz5 & & MKRLILRTFVML ATGGCAAA & 404 & \\
\hline Spz6 & & MARRIFIFLTLLLI ATGGCACG & 390 & \\
\hline Spz7 & & MASVTLMFTVV ATGGCGTC & 184 & \\
\hline Toll1 & BmToll3_2 & MQARRWCAAL atgcaggctc\& & 960 & \\
\hline Toll2 & BmToll3_1 & MRSLWLTLTLAL ATGCGGTC & 973 & \\
\hline Toll3 & BmToll3_3 & MQARRWCAAL Atgcaggctc & 961 & \\
\hline Toll4 & BmToll3_4 & MQARRWCAAL ATGCAGGC & 966 & \\
\hline Toll5 & BmToll3_5 & MQAWRWWCT ATGCAGGC & 961 & \\
\hline Toll6 & & MALRQVSSRQF ATGGCTCT, & 1279 & \\
\hline Toll7_1 & & MDTVPFIMIINV ATGGACAC & 1253 & \\
\hline Toll7_2 & & MYAIAAVFCALL ATGTACGC & 1295 & \\
\hline Toll7-3 & & MFQLLTLLFVTFIATGTTTCA & 1282 & \\
\hline Toll8 & & MLFTWLSNALLIATGTTGTT & 1279 & \\
\hline Toll9_1 & & MLLIRYLWLLLC' ATGCTGTTI & 853 & \\
\hline Toll9_2 & & MLWRFLEVLLLVATGTTGTG & 753 & \\
\hline Toll10_1 & LRR-TMP22 & MPIKPILAKRLEVATGCCAAT. & 1345 & \\
\hline Toll10_2 & & MMKNFCGMISI ATGATGAA & 1343 & \\
\hline Toll10_3 & & MLSMGLLTVW $\backslash$ ATGTTATC 7 & 1339 & \\
\hline Toll12 & LRR-TMP14 & MRVVSAALALQ ATGCGTGT & 795 & \\
\hline ML1 & DmML1 & MLFYITVTVLLV $\subseteq$ ATGTTGTT & 145 & \\
\hline ML2 & DmML6 & MAALHWFLLAA ATGGCGGC & 151 & \\
\hline ML3 & DmML3 & MLRWYYVFIFFA ATGTTGCG & 170 & \\
\hline ML4 & DmML8 & MGKKLQVFLLLC ATGGGTAA & 157 & \\
\hline ML5 & DmML5 & MFPLSAVACLVL ATGTTTCC & 155 & \\
\hline MyD88 & & MCKLTPGNMAE ATGTGTAA & 412 & \\
\hline Tube & & MDRNLELRKLPI ATGGATAG & 612 & \\
\hline Pelle & & MYIYQLPFEINRI ATGTACAT، & 490 & \\
\hline Pellino & & MGYKCRVQDLC ATGGGTTA & 419 & \\
\hline Cactus & & MSAKKGYETKIV ATGAGTGC & 322 & \\
\hline Dorsal-A & & MDVGGDAAVIL ATGGACGT & 387 & \\
\hline Dorsal-B & & MFVTLCGGNYSI ATGTTTGTI & 415 & \\
\hline Dorsal-C & & MAHTQPQPLQI ATGGCGCA & 688 & \\
\hline Dif-A & & MALSRPRQLQT|ATGGCTCTI & 631 & \\
\hline Dif-B & & MALSRPRQLQT|ATGGCTCTI & 450 & \\
\hline Tollip-1 & & MASTMQLEFTC ATGCAGCT & 244 & \\
\hline Tollip-2 & & MTSTMPNDRNI ATGACTTC, & 278 & \\
\hline TRAF2 & & MDRARTKDASE ATGGATCG & 417 & \\
\hline Ref2P-A & & MESEVQFKTYTF ATGGAATC & 656 & \\
\hline Ref2P-B & & MESEVQFKTYTF ATGGAATC & 651 & \\
\hline Ref2P-C & & MESEVQFKTYTF ATGGAATC & 649 & \\
\hline
\end{tabular}


Fig. 1

A

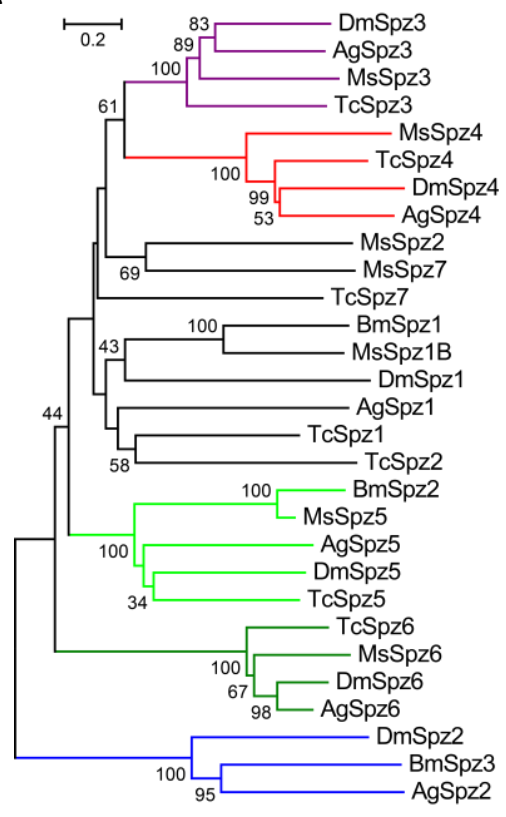

B

--DTPDIAQRLG------PQEDNMELCSFREKIFYPKAAPDKDGNWF

--FIEAYGDRQG-------DPDAFDNCDTEVTYEPLYKVRSARGQWH RHARQAANTPLP-DAQAVNSTGRVDACESKTEIMTPYWALNSARKLR EEFHPKPLQHQDTTRPSF IKLRGANACETKESLEAPFWANSTRGEVL MASAETSAERPR-----RQAAAAEELCRVRTEFITPRAALNNKGNWK --PAAPHAQHPN--MPYHRYEGPPTPCPARVEYATPVFARNYQGVWR --NYNYDYQAREYT--------FENNCNYVKEMSTPYLVHSN-GTAK 2 3

FVVNSKE--NPVQGYKVEICDRQQLP--CAEFA---SFQQGYEARCI TVIQAPEE-NYIQKVRLETCKEVESS--CETAV--SSLVPTITTFCK

AIVNTM---HFEQAIHQETCSKTTTNR-CNRDC-----------GCE

ALLNLY---PYEQYIHLETCVHERKQMYCREGC-----------RCE

YVVNMPD--NMTQLVRAEICASTT----CSGLC---TIPAGYSSRCE

YVVQIPYEGYFTQTVEVTRCMQSR----CHYLE----------GGCL

IIVQTS---FYKQRFMTTRCVDSFSNAADGEQCFKGILSGNSRGSCK

$$
423
$$

QKYVRRTMLA---LDPKG-----QMTDMPLKVPSCCSCVAKLTII *

QKYSVWQVLV---SDGNN-----GTEPIKVELPICCSCHYKMNDNK*

QKYKWHRLLA---YDPSDD--CAGIFMDWFLFPSCCVCRCKP*

QQYRLHRLLA---YDPHNA--CRGIFADWFRFPACCVCKCYDVPPVE...

QKYIQKRLVA---LESSG----QNLYTDVFWIPSCCQCSITPN*

SSPRWVSLLVAELHYPAQQQNLQVRYTACFKII IACQKQFQF*

TKYTNI ILYA---YDEAN----KRIQRLPIEVPVCCYCGITSEFD* 
Fig. 2 (continued on the next page)

tissue: head fat body whole midgut MT muscle testis ovary

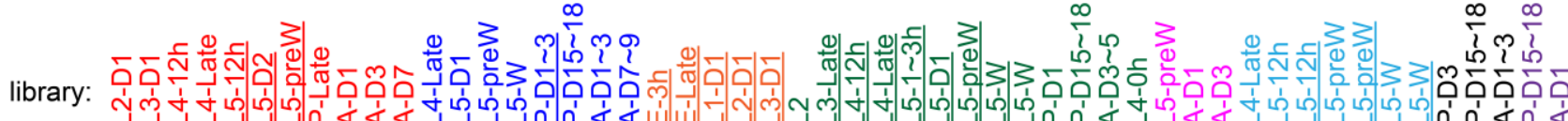

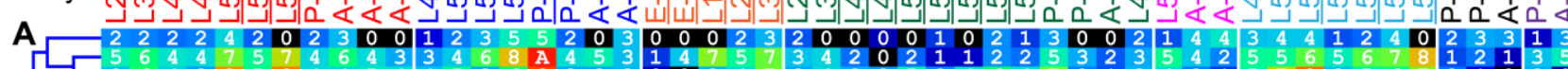

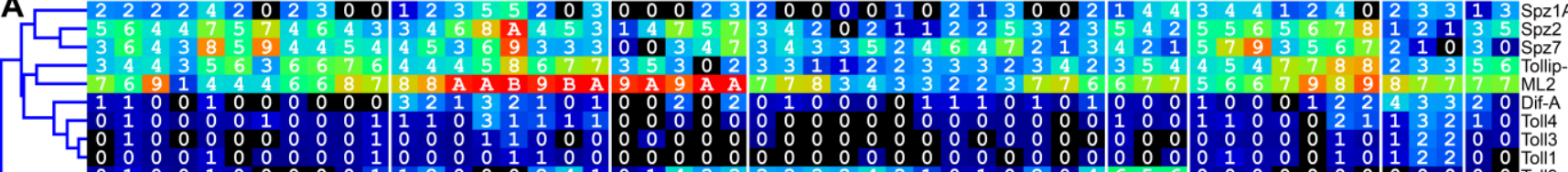

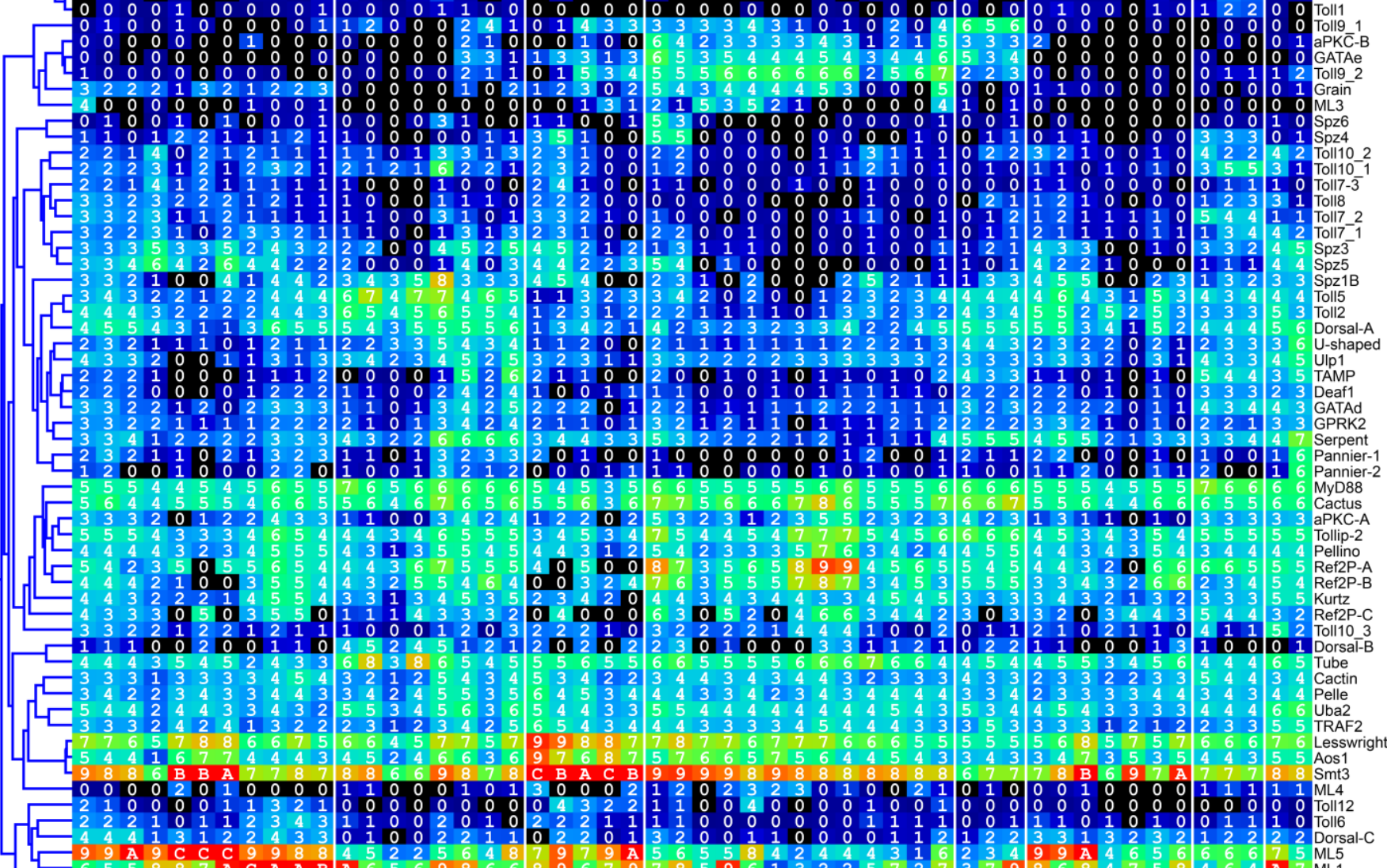

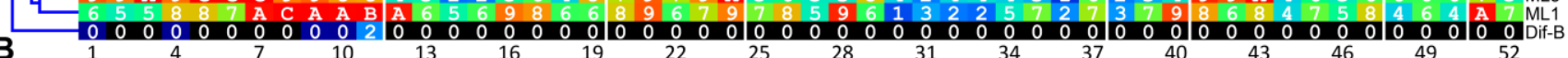

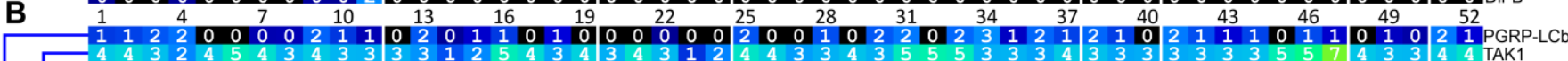

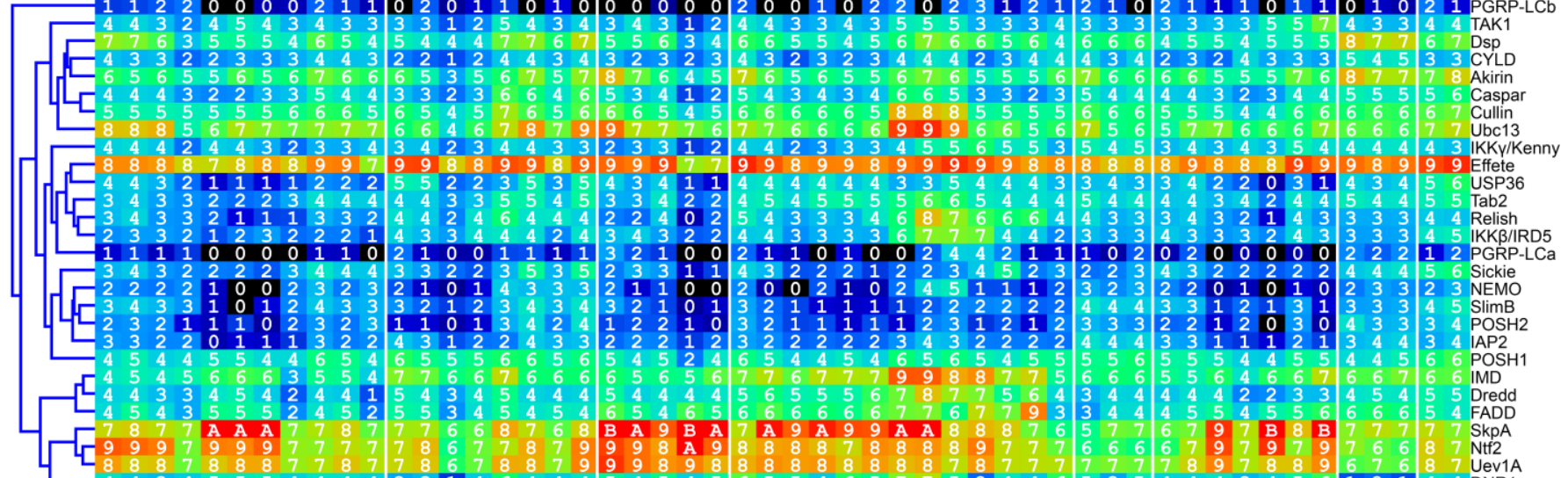

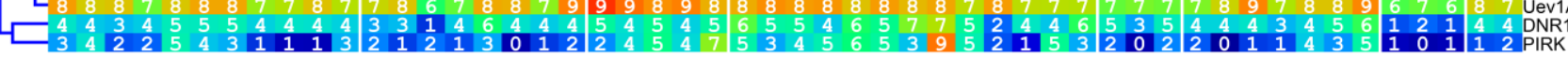
$\begin{array}{llllllllllll}1 & 4 & 10 & 13 & 16 & 19 & 22 & 25 & 28 & 31 & 34 & 37\end{array}$ 0 
tissue: head fat body whole midgut MT muscle testis ovary

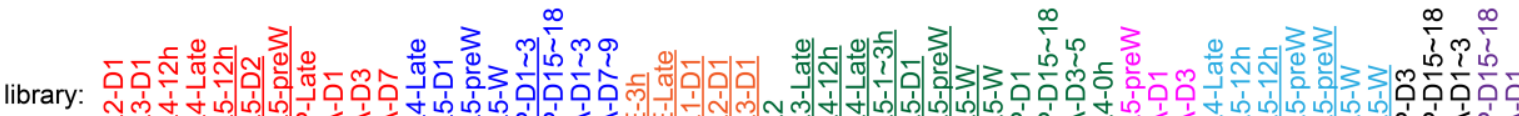

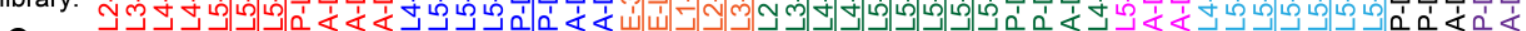

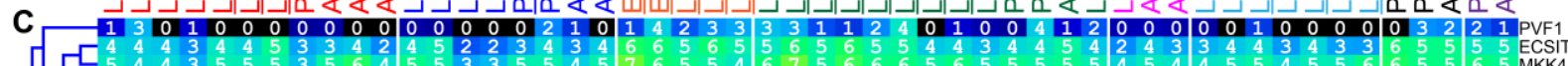

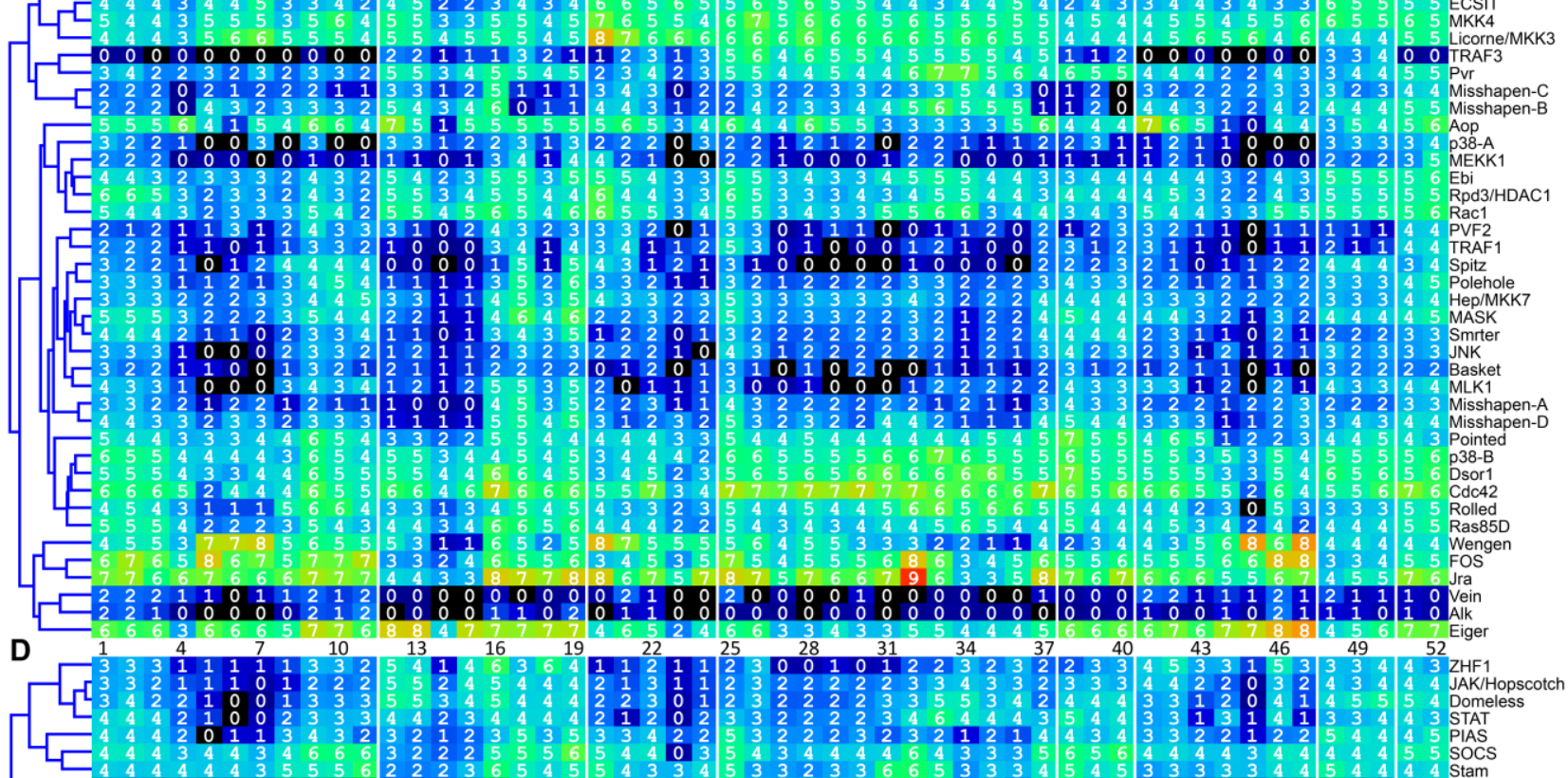

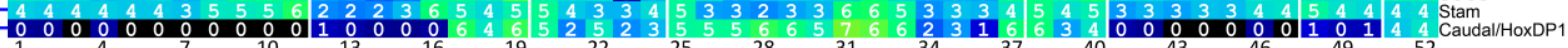

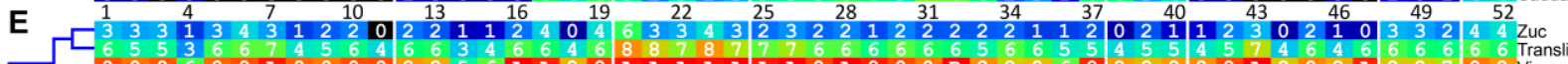

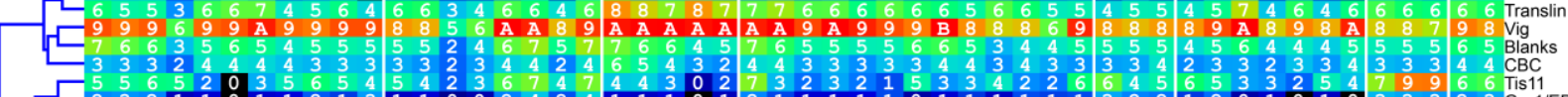

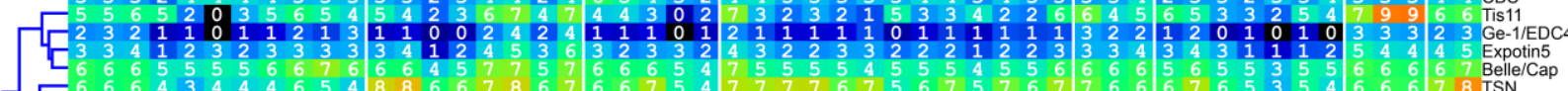

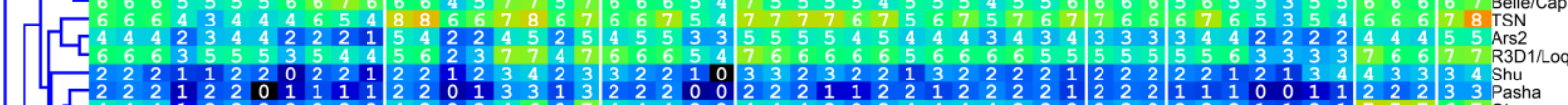

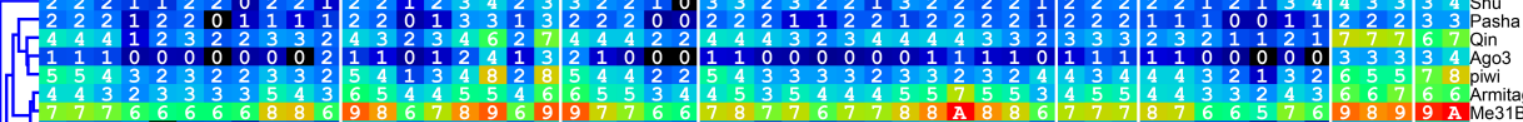

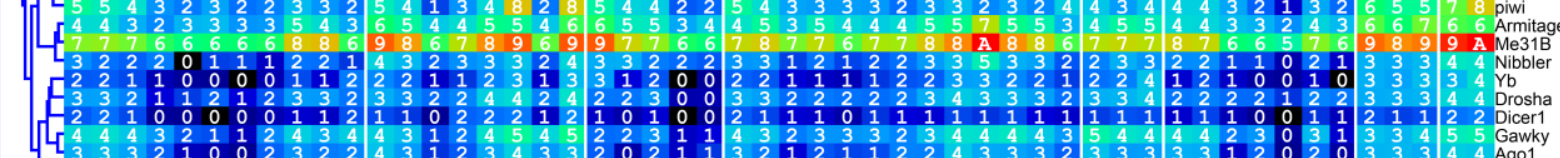

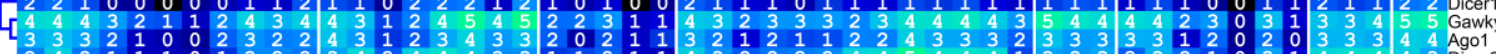

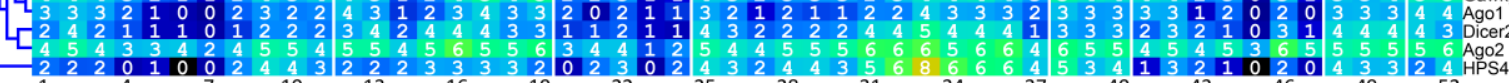

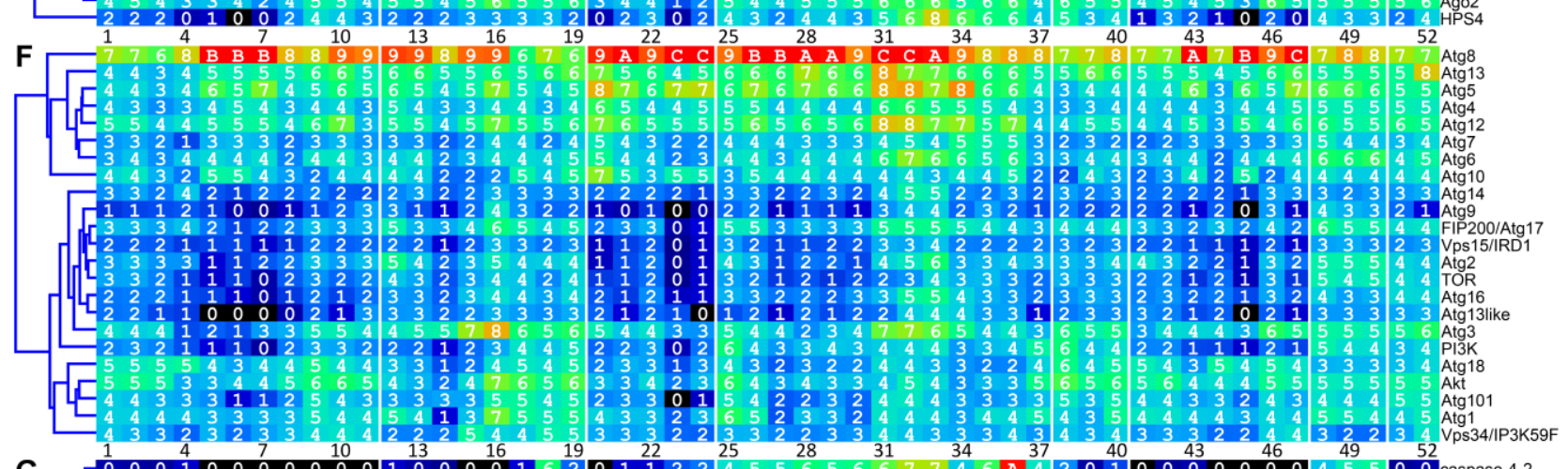

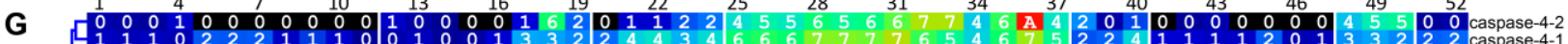

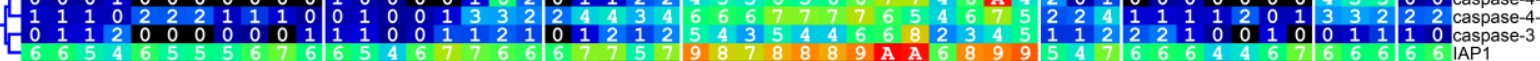

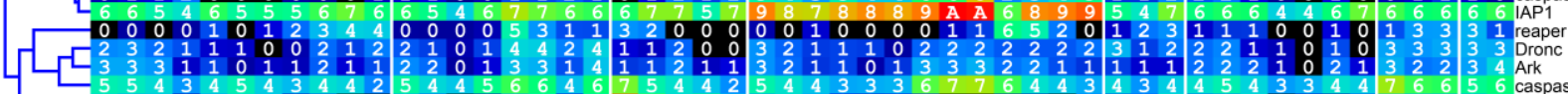

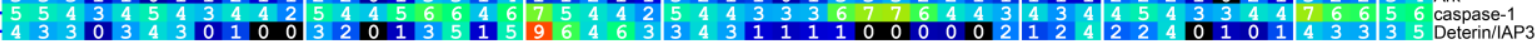


Fig. 3

A

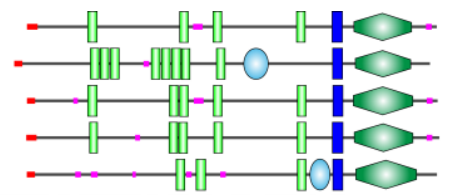

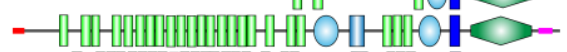

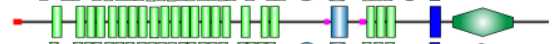

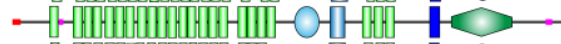

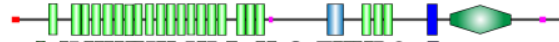

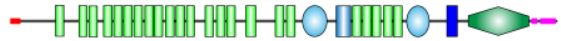
-

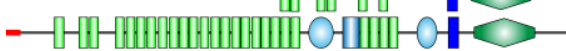

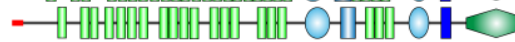

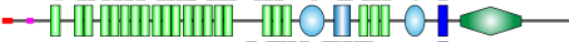

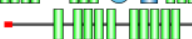

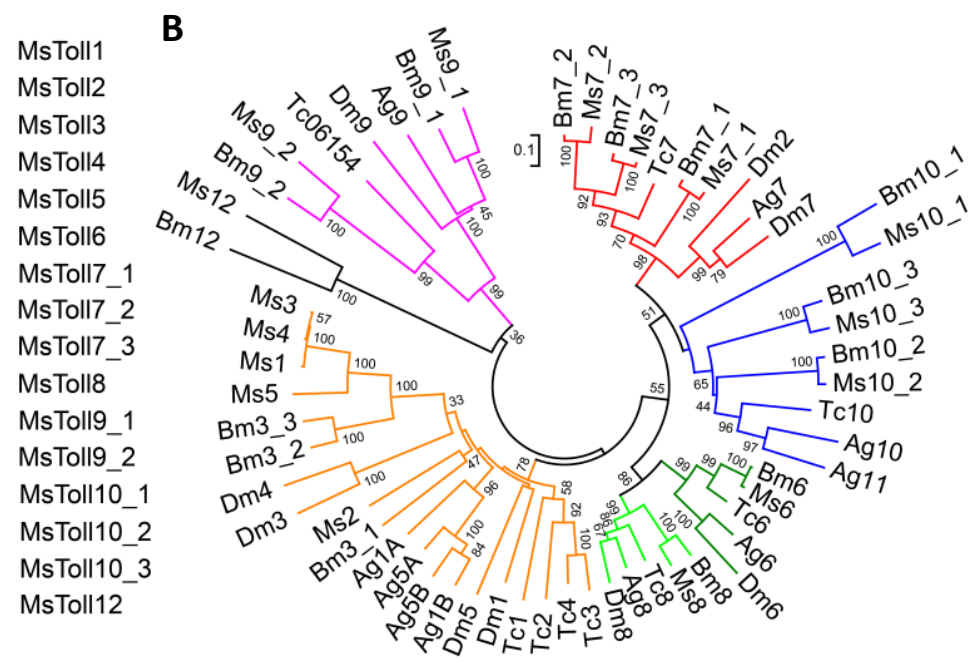

B

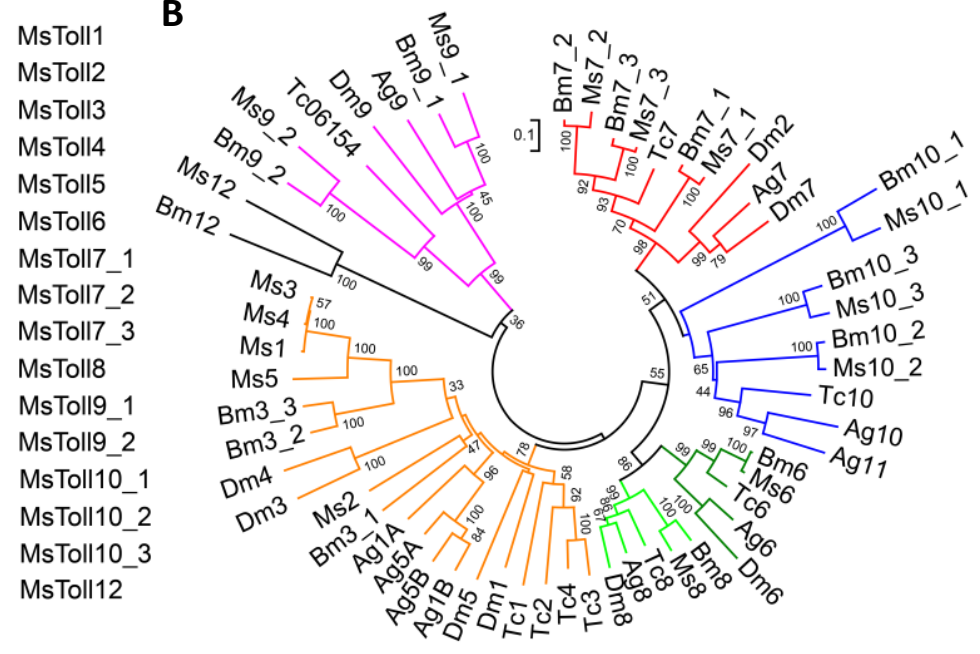

C

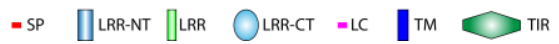
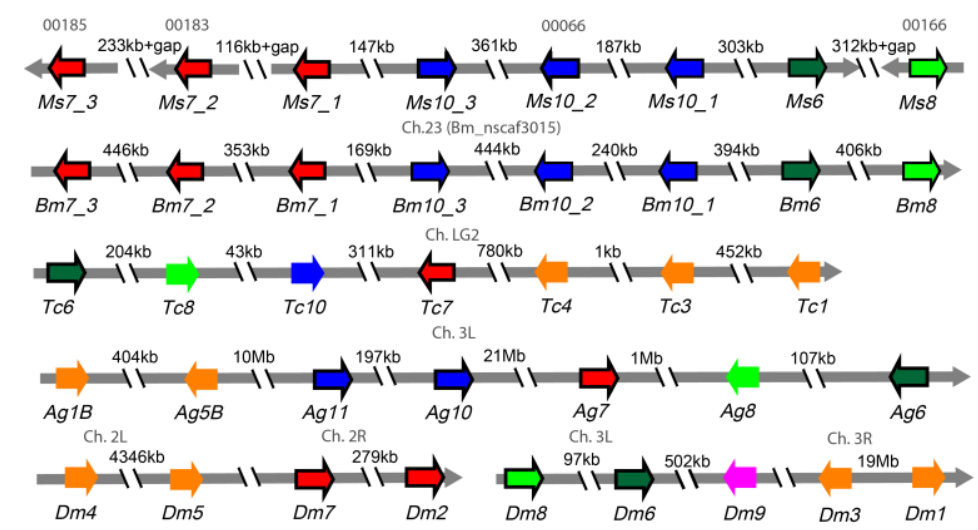
Fig. 4
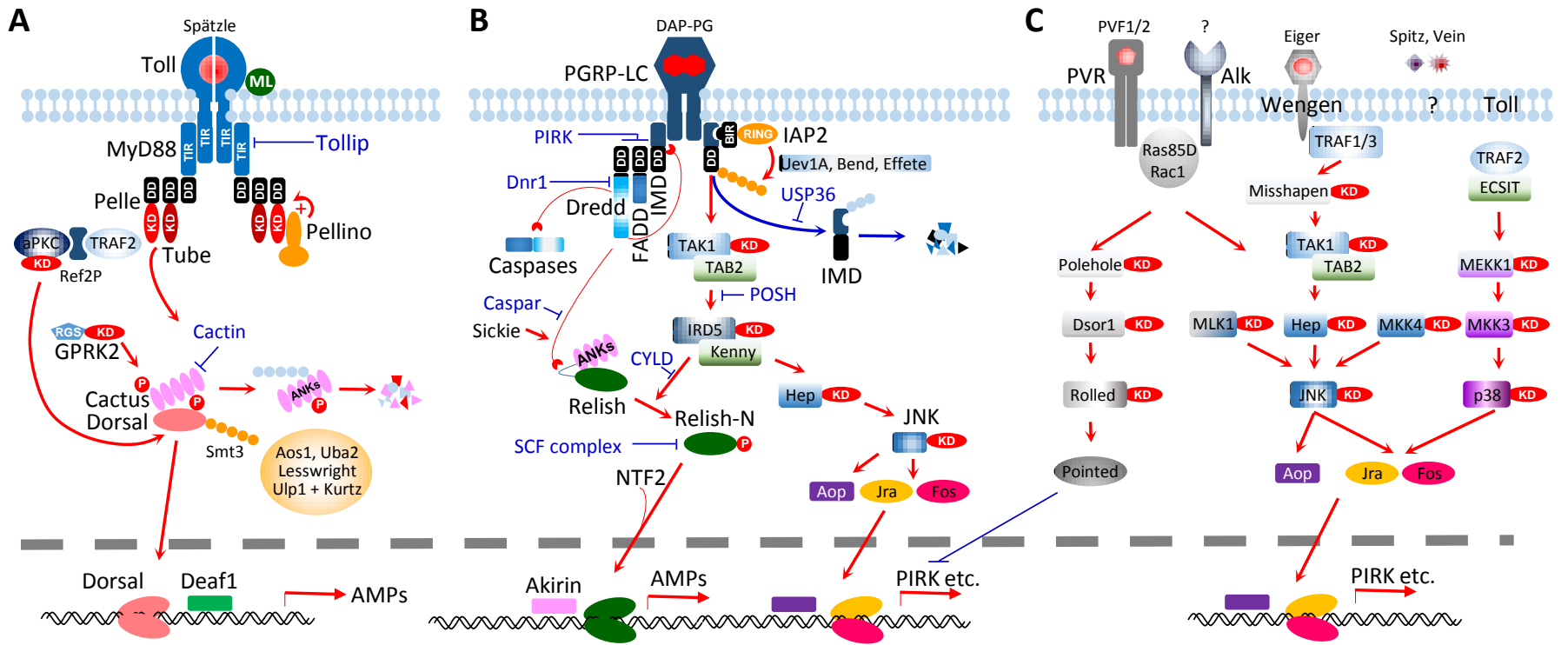

Dorsal Deaf1 $\longrightarrow$ AMPs

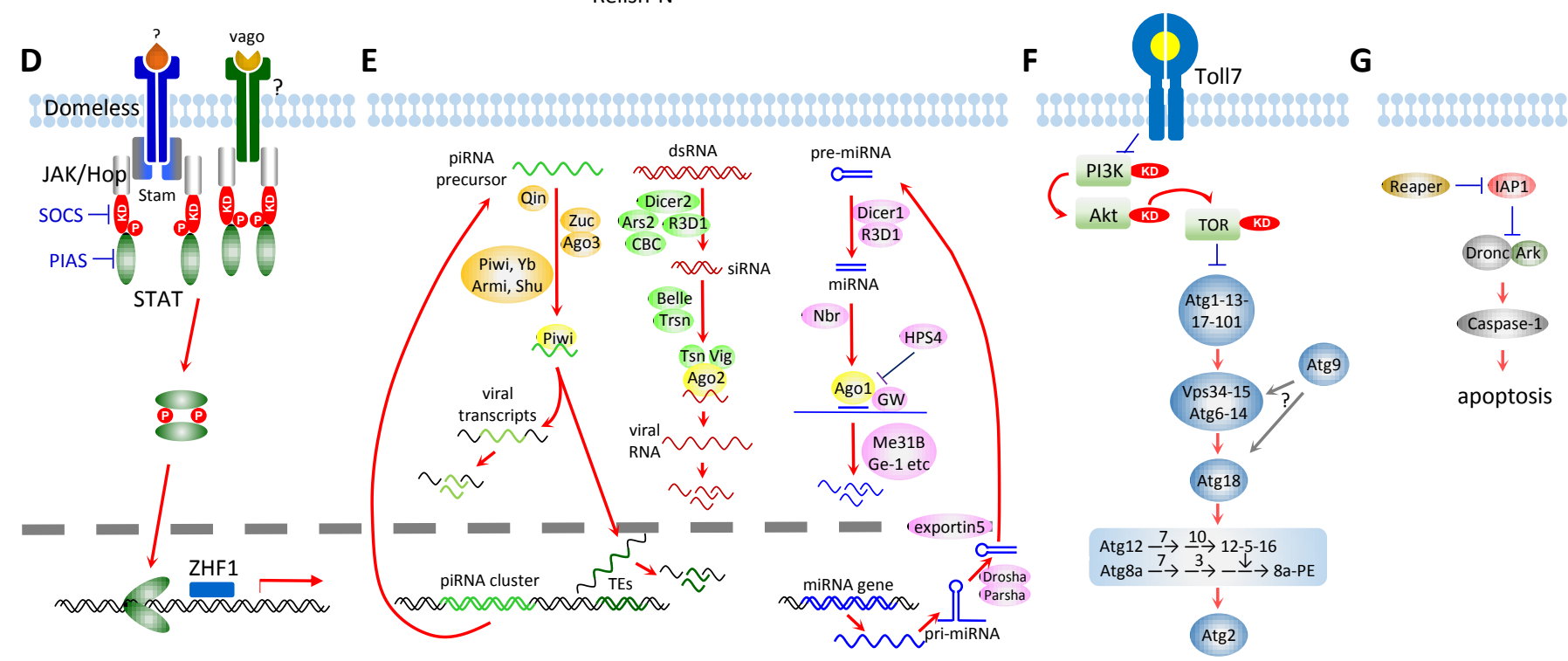




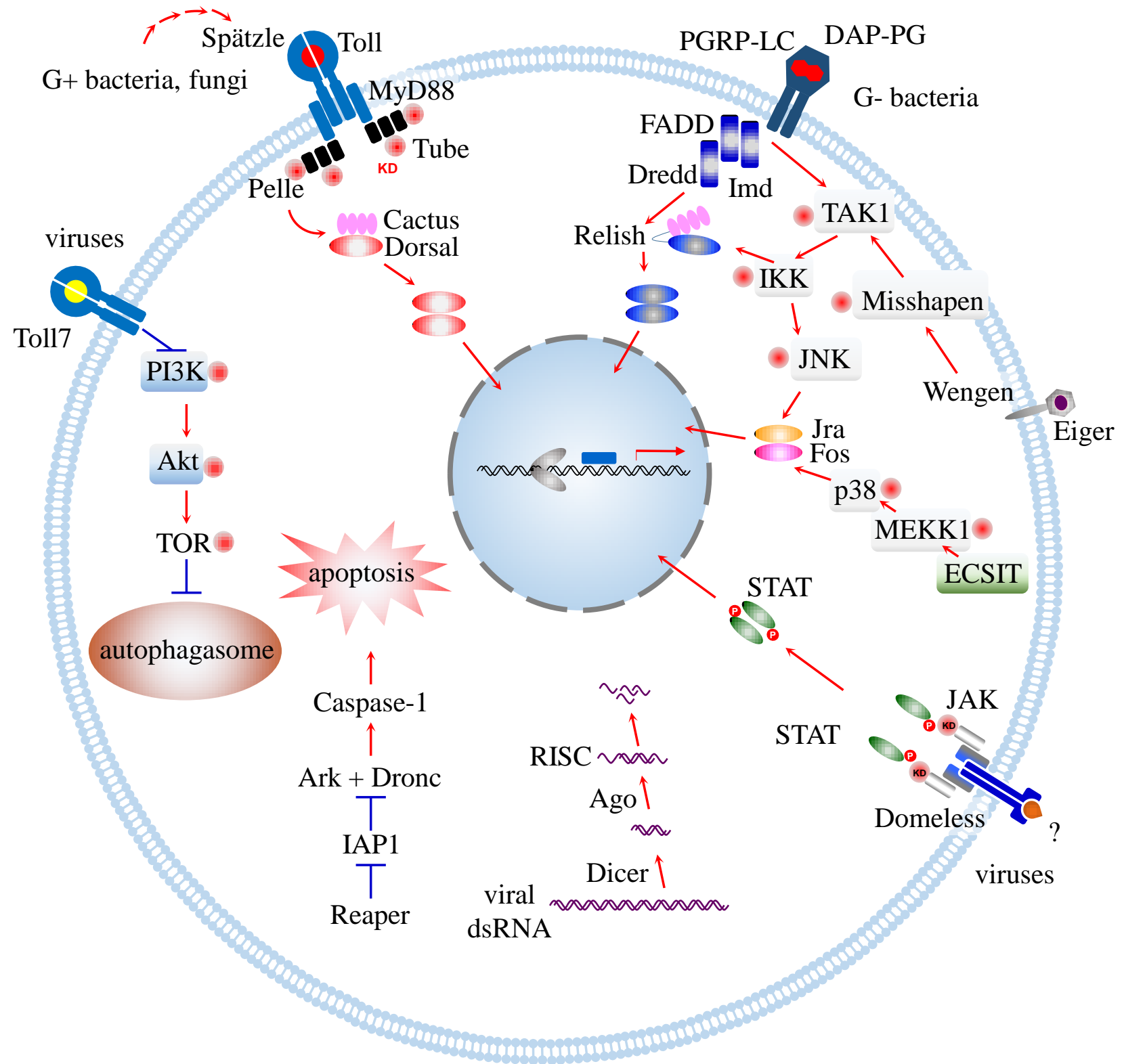

